Illinois State University

ISU ReD: Research and eData

Theses and Dissertations

$10-17-2013$

\title{
Personal Characteristics and Learning Preference in End-of-Life Decision Making of Chronically III Community Dwelling Elders
}

Leigh Ann Bonney

Illinois State University, kevleighb@yahoo.com

Follow this and additional works at: https://ir.library.illinoisstate.edu/etd

Part of the Family, Life Course, and Society Commons, Nursing Commons, and the Public Health Education and Promotion Commons

\section{Recommended Citation}

Bonney, Leigh Ann, "Personal Characteristics and Learning Preference in End-of-Life Decision Making of Chronically III Community Dwelling Elders" (2013). Theses and Dissertations. 78.

https://ir.library.illinoisstate.edu/etd/78

This Dissertation is brought to you for free and open access by ISU ReD: Research and eData. It has been accepted for inclusion in Theses and Dissertations by an authorized administrator of ISU ReD: Research and eData. For more information, please contact ISUReD@ilstu.edu. 
PERSONAL CHARACTERISTICS AND LEARNING PREFERENCES IN END-OF-LIFE DECISION MAKING OF CHRONICALLY ILL COMMUNITY DWELLING ELDERS

\section{Leigh Ann Bonney}

87 Pages

May 2014

This paper is a culmination of three manuscripts, to be submitted for publication, exploring end-of-life decision making. The first paper, a concept analysis of decisional conflict, defines and analyzes the concept. Antecedents included insufficient time, minimal and extreme stress, anticipated consequences, stakeholder reactions, selfreactions, and no acceptable options. Defining attributes included uncertainty, concern for outcomes, questioning moral principles, personal values, wavering, and delayed decision making. The consequences were anxiety, regret, poor decision making, stress and physical symptoms. The Decisional Conflict Scale, a valid and reliable tool, is an empirical referent.

The second manuscript is a systematic review of end-of-life decision-making literature which identified factors associated with decisional conflict and preferences for type of decision aid to assist learning. The participants' mean age was 60 . Studies $(n=14)$ were rated for quality utilizing the Johns Hopkins Research Evidence Appraisal Tool. Three rated "good"; six rated "high"; five rated "low" in quality. Personal characteristics 
associated were race, older age, and limited health literacy. Older participants preferred fewer learning methods, while women and higher educated individuals favored variety. Patient and physician communication is poor, but decision making can be enhanced through decision aids.

The third manuscript reports an exploratory descriptive study of end-of-life decision making of 115 chronically ill community-dwelling adults, mean age 81.6 years, $\mathrm{SD}=4.97$, in Central Illinois. This study, guided by The Ottawa Decision Support Framework, research questions were personal characteristics leading to decisional conflict and preferences for decision aid, and feasibility of online survey methodology. Participants completed several scales: Population Needs Assessment, Newest Vital Sign, Symptom Distress Scale, and the Decisional Conflict Scale. Most felt knowledgeable about end-of-life options and treatments. Findings suggest women prefer to learn by talking to healthcare providers. Higher educated individuals have less decisional conflict. Fifteen surveys were completed online, so online completion does not appear feasible. 
PERSONAL CHARACTERISTICS AND LEARNING PREFERENCES IN END-OF-LIFE DECISION

MAKING OF CHRONICALLY ILL COMMUNITY DWELLING ELDERS

\section{LEIGH ANN BONNEY}

A Dissertation Submitted in Partial

Fulfillment of the Requirements

for the Degree of

DOCTOR OF PHILOSOPHY

Mennonite College of Nursing

ILLINOIS STATE UNIVERSITY 
Copyright 2014 Leigh Ann Bonney 
PERSONAL CHARACTERISTICS AND LEARNING PREFERENCES IN END-OF-LIFE DECISION MAKING OF CHRONICALLY ILL COMMUNITY DWELLING ELDERS

\section{LEIGH ANN BONNEY}

COMMITTEE MEMBERS:

Susan P. Kossman, Chair

Caroline Mallory

Wendy Woith

MyoungJin Kim 


\section{ACKNOWLEDGMENTS}

This dissertation is dedicated first and foremost to the two loves of my life, my husband, Kevin, and my wonderful, son, Austin. I could not have survived this entire process without the love, laughter, support and patience you have given me these past

years. I am so lucky to have you both in my life, and I hope I have made you both proud. I worship you! I would like to also thank Newman and Brutus who were at times distracting, but mostly freely giving of unconditional love and stress reduction. I thank my parents, brothers and sisters, and best friends for their love and support.

I am blessed and grateful to have a work family at OSF Saint Francis Medical Center College of Nursing who all work together so well to help take the pressure off when school commitments were overwhelming. I thank my bosses, Dr. Patricia Stockert and Dr. Sue Brown, for being understanding and generous.

Lastly, I would like to thank my committee members, Drs. Susan Kossman, Caroline Mallory, Wendy Woith, and MyoungJin Kim, without whom this accomplishment would never have come to fruition. Their expertise, guidance, and encouragement were invaluable. I would like to especially thank my committee chair, Dr. Susan Kossman for her fabulous guidance. Her expertise in research and scholarly 
writing has helped my writing improve immensely. She has been instrumental in my success. While her knowledge and expertise were greatly appreciated, it was her love and support that were most valued and will always be cherished. I would like to acknowledge Dr. Caroline Mallory for her encouragement and expertise. I would also like to acknowledge Dr. Wendy Woith for her review of my manuscripts and attention to detail. Thanks to Dr. Kim for his help and guidance with the statistical analyses in this study. He was "significantly" helpful. I would not have been able to complete this dissertation without these incredible individuals.

I would like to thank the faculty, staff, and all my peers at Mennonite College of Nursing for being so kind and helpful throughout this entire process. I am grateful for the resources extended to me to aid in my success. I would like to especially acknowledge Melissa Moody for her positive attitude. She was always helpful, kind, and calming to a frazzled doctoral student.

Lastly, I would like to thank Nurse Educators of Illinois and the Mennonite College of Nursing for grants to help fund my research. 


\section{CONTENTS}

Page

ACKNOWLEDGMENTS

CONTENTS

TABLES

vi

FIGURES

vii

CHAPTER

I. ANALYSIS OF THE CONCEPT OF DECISIONAL CONFLICT

Abstract

1

Purpose and Method of Analysis

Uses of the Concept

Dictionary definition

Decision

4

Conflict

4

Decisional conflict

5

Decisional conflict in decision making

Defining Attributes

A Model Case

A Contrary Case

A Borderline Case

Antecedents

Decision making

Stress

Personal characteristics

15

iii 
II. A SYSTEMATIC REVIEW: PERSONAL CHARACTERISTICS AND LEARNING PREFERENCES IN END-OF-LIFE DECISION MAKING

Abstract

Methods

Results

Designs of Studies

Description of Studies

Sample

Quality of the Studies

Decisional conflict

Personal characteristics associated

Use of decision aids

48

Preferences for type of decision aid 


\section{PERSONAL CHARACTERISTICS AND LEARNING PREFERENCES IN END-OF-LIFE DECISION MAKING OF CHRONICALLY ILL COMMUNITY \\ DWELLING ELDERS: AN EXPLORATORY STUDY}

Abstract

Purpose

$\begin{array}{ll}\text { Theoretical Framework } & 60\end{array}$

Literature Review

Personal Characteristics Associated with Decisional Conflict

Decision Aids

Preferences for Type of Decision Aid

Methods

Procedure

Results

Sample Characteristics

Question 1: Personal Characteristics Associated with Decisional Conflict

Question 2: Variables Associated with Preferences

for Type of Decision Aid

Question 3: Feasibility of Online Surveys with Older, Chronically III Elders

Discussion

Limitations

Implications for Practice 


\section{TABLES}

Table

Page

1-1. Defining Attributes, Antecedents, and Consequences

2-1. Summary Table of Reviewed Studies

30

2-2. Sample Demographics

37

2-3. Sources of Potential Study Bias and Quality Rating

3-1. Instrument, Descriptions, and Psychometrics

66

3-2. Sample Characteristics ( $N=115) \quad 70$

3-3. Multiple Linear Regression

72

3-4. Analysis of Predictor Variables of Preference for Type of Decision Aid

73 


\section{FIGURES}

$\begin{array}{lll}\text { Figure Page } & \text { Pag }\end{array}$

1. Ottawa Decision Support Framework 61 


\title{
CHAPTER I
}

\section{ANALYSIS OF THE CONCEPT OF DECISIONAL CONFLICT}

\begin{abstract}
Making a decision can be difficult, but healthcare decisions can be especially challenging due to their complexities. When individuals feel ill prepared to make a decision, they may experience decisional conflict (Janis \& Mann, 1977). The purpose of this paper is to define and analyze the concept of decisional conflict in order to make the concept more useful to healthcare providers. This analysis employed the guidelines of Walker and Avant (2005) to explore its historical use, identify defining attributes, present a model case, a contrary case, and a borderline case of the concept and identify empirical referents.

Janis (1959), a psychologist, defined decisional conflict “opposing tendencies within an individual, which interfere with the formulation, acceptance, or execution of a decision". Antecedents include insufficient time to devote to the decision, very little and extreme stress, anticipated consequences, stakeholder reactions, self-reactions, and no acceptable options. Defining attributes include verbalized uncertainty, concern for outcomes, questioning moral principles, personal values, wavering, and delayed decision making. The consequences identified were anxiety, post-decision regret, poor decision making, stress and symptoms such as agitation, sleeplessness, loss of appetite,
\end{abstract}


and tachycardia. The Decisional Conflict Scale is a valid and reliable tool to measure the concept.

Making a decision can be difficult, but making decisions about healthcare issues can be especially challenging due to their complex nature. Decision making is defined as choosing between a minimum of two options ( $\mathrm{O}^{\prime}$ Connor et al., 1998). People face many decisions throughout their lifetime, and the number of healthcare decisions faced tends to increase with age. When individuals feel ill prepared to make a decision, they may experience decisional conflict (Janis \& Mann, 1977). The concept of decisional conflict describes feelings of uncertainty and is common in healthcare decisions involving risk and uncertain outcomes (O'Connor, 1999). Manifestations of decisional conflict include feelings of uncertainty, expressing uncertainty, verbalizing the unwanted consequences of alternative choices, going back and forth between choices, and ultimately delaying decision making (O’Connor, 1999).

Delaying decision making can have dire consequences in healthcare. For instance, delaying making a decision about having screening tests could result in development of a condition which might have been prevented or if caught early, treated, and cured. People who experience decisional conflict about end-of-life care may delay making important decisions and this could result in them receiving potentially unwanted care by default. This is not a trivial problem; receiving unwanted lifesustaining treatment can result in physical and emotional stress for patients and families and excessive healthcare costs. Estimates of Medicare costs, in the last few years of life, range from $\$ 53,000$ to $\$ 93,842$ (Turk, 2009). Recognizing and addressing decisional 
conflict can lead to increased decision-making quality and end-of-life decisions that reflect the individual's wishes.

\section{Purpose and Method of Analysis}

The purpose of this paper is to define and analyze the concept of decisional conflict in order to make the concept more useful to healthcare providers. I will use the guidelines presented by Walker and Avant (2005) to explore its historical use, identify defining attributes, present a model case, a contrary case, and a borderline case of the concept and identify empirical referents. Walker and Avant (2005) streamlined Wilson's (1963) 11-step concept analysis process into eight steps listed below. This approach is straightforward and clearly guides the writer through the concept analysis.

1) Select a concept.

2) Determine the aims or purposes of analysis.

3) Identify all uses of the concept that you can discover.

4) Determine the defining attributes.

5) Identify a model case.

6) Identify borderline, related, contrary, invented, and illegitimate cases.

7) Identify antecedents and consequences.

8) Define empirical referents.

A search of Cumulative Index to Nursing and Allied Health Literature (CINAHL), PubMed, PsychInfo, Google Scholar, and Medline using "decisional conflict" as the search term uncovered 979 resources. Titles and abstracts were reviewed to eliminate duplicates and identify those that met inclusion criteria (included a definition of 
decisional conflict, had decisional conflict as the main focus of the paper rather than an outcome of a study; were published in English from 1998-2013). The resultant group of literature reviewed included 18 articles, one book and two book chapters.

\section{Uses of the Concept}

Dictionary definition. The Merriam-Webster Online Dictionary was used as the source of general dictionary definitions. This dictionary does not include a definition of "decisional conflict" so instead definitions of each word were located in this source.

Decision. The word "decisional" is an adjective related to decision. The word "decision", dating back to the $15^{\text {th }}$ century, is derived from the Middle English word decisioun, from Middle French, from Latin decision-, decisio, from decidere to decide. "Decision", a noun, has four meanings listed:

1) a: the act or process of deciding $b$ : a determination arrived at after consideration

2) a report of a conclusion

3) promptness and firmness in deciding

4) a: win; specifically: a victory in boxing decided on points $b$ : a win or loss officially credited to a pitcher in baseball (decision, n.d., para 2)

Conflict. The word "conflict" dates back to the $15^{\text {th }}$ century and is Middle English, from Latin conflictus act of striking together, from confligere to strike together, from com- + fligere to strike. "Conflict", a noun, has three definitions listed fight, battle, war 
1) a: competitive or opposing action of incompatibles: antagonistic state or action (as of divergent ideas, interests, or persons)

$b$ : mental struggle resulting from incompatible or opposing needs, drives, wishes, or external or internal demands

2) the opposition of persons or forces that gives rise to the dramatic action in a drama or fiction (conflict, n.d., para 2)

The Merriam Webster online dictionary lists two clinical definitions of "conflict". The medical definition is "a mental struggle resulting from incompatible or opposing needs, drives, wishes, or external or internal demands" (conflict, n.d., para 6), and In psychology, the definition of conflict is a struggle resulting from incompatible or opposing needs, drives, wishes, or demands. Interpersonal conflict represents such a struggle between two or more people, while internal conflict is a mental struggle. A child experiencing internal conflict, for example, may be dependent on his mother but fear her because she is rejecting and punitive. Conflicts that are not readily resolved may cause the person to suffer helplessness and anxiety (conflict, n.d., para 11).

Decisional conflict. The first definition of decisional conflict found in the literature came from a psychologist, Janis, who defined it in 1959 as "opposing tendencies within an individual, which interfere with the formulation, acceptance, or execution of a decision" (p. 7). Janis (1959) defined decision as "any act, symbolic or overt, which is socially defined as a commitment to carry out a specified task, to take on 
the responsibilities of a specified social role, or to execute a specified course of action in the future" (p. 6) and can be used when the decision maker is a representative of a group or is acting on their own behalf. The word decisional is an adjective, and in this case describes which type of conflict. Later, Janis and Mann (1977) refined the definition of decisional conflict to "simultaneous opposing tendencies within the individual to accept and reject a given course of action" (p.46). The North American Nursing Diagnosis Association (NANDA) (1990) defined decisional conflict as the "state of uncertainty about which course of action to be taken when choice among competing actions involves risk, loss, or challenge in personal life values" (p. 69). Both definitions speak of opposing choices, but the NANDA definition introduces uncertainty, risk, and loss into the definition.

O'Connor offered multiple definitions of decisional conflict. She added the concept of regret to prior definitions by defining decisional conflict as a state of uncertainty about the course of action to take. This state is likely when making choices involving risk or uncertainty of outcomes, high stakes in terms of potential gains and losses, the need to make value tradeoffs in selecting a course of action, and anticipated regret over the positive aspects of rejected options (1995, p. 25).

In 1997, O'Connor expanded the definition to add "challenge to personal life values (...such as personal health, family relationships, career, finances, or other life events)" to risk, loss and regret (p. 486). O'Connor et al.'s 1998 definition further expanded the concept to 
uncertainty about course of action to take arising from factors inherent in the decision (uncertainty of outcomes, or the need to make value tradeoffs between benefits and risks) and modifiable factors (inadequate knowledge, unrealistic expectations, unclear values and norms, unwanted social pressure, inadequate social support, lack of other resources) (p. 270).

The National Institute of Health $(\mathrm{NIH})$ database of behavioral, social science, and scientific measures, defines decisional conflict as a measurement of personal perceptions of : a) uncertainty in choosing options; b) modifiable factors contributing to uncertainty such as feeling uninformed, unclear about personal values and unsupported in decision making; and c) effective decision making such as feeling the choice is informed, values-based, likely to be implemented and expressing satisfaction with the choice (Tsakraklides, 2011, para 1).

By defining decisional conflict as a measurement, this definition highlights decisional conflict as an instrument that takes action rather than a noun. This definition describes more what it does than what it is as in previous definitions.

Decisional conflict in decision making. Janis (1959) identified three sources of decisional conflict: anticipated consequences of the decision, anticipated approval or disapproval of key stakeholders, and self-reactions guided by the individual's moral standards and values. These three components combine together to influence the individual's decision making. This involves exploring what will be gained and lost from 
making the decision. Janis and Mann (1976) warn that the general reason for poor decision making is attempting to avoid decisional conflict instead of merely addressing it.

Hiltunen, Chase, and Medich, (1999) identified stages individuals may experience in end-of-life decision making. These stages were recognizing the dilemma, vacillation, moving to a turning point and letting go. In the dilemma phase, the individual feels no acceptable options exist. This is the beginning of decisional conflict. Vacillation can also be interpreted as ambivalence. The individual bounces between options and poses many questions. Moving to a turning point takes time and permits the plan to evolve or develop. This is when the individual is learning about new options. Letting go completes the decision making process. The person has made new meaning of the situation. In end of life, oftentimes this is when the person realizes it is okay to stop treatment and let go.

\section{Defining Attributes}

Walker and Avant (2005) identified defining attributes as the heart of concept analysis. Defining attributes are those most frequently associated with the concept and allow a general insight into the concept. Defining attributes of decisional conflict include verbalized uncertainty (Hiltunen, 1994; O’Connor, 1997; O’Connor \& Jacobsen, 2001; Ralph \& Taylor, 2013), concern over negative outcomes (O’Connor, 1997;

O’Connor \& Jacobsen, 2001; O’Connor \& Legare, 2012; Ralph \& Taylor, 2013), wavering between choices (Hiltunen, 1994; Mcfarland \& Mcfarlane, 1989; O’Connor \& Jacobsen, 2001; O’Connor \& Legare, 2012; Ralph \& Taylor, 2013), delaying decision making (Hiltunen, 1994; Mcfarland \& Mcfarlane, 1989; O’Connor, 1997; O’Connor \& Jacobsen, 
2001; O'Connor \& Legare, 2012; Ralph \& Taylor, 2013), being preoccupied with decision making (O'Connor \& Jacobsen, 2001; O'Connor \& Legare, 2012), exhibiting signs of tension or stress (Hiltunen, 1994; O'Connor, 1997; O'Connor \& Jacobsen, 2001;

O'Connor \& Legare, 2012; Ralph \& Taylor, 2013), focusing on self (Hiltunen, 1994; Ralph \& Taylor, 2013), being preoccupied with the decision, (O'Connor \& Legare, 2012), and verbalizing undesired consequences of alternative actions (Hiltunen, 1994; O'Connor, 1997; O’Connor \& Legare, 2012; Ralph \& Taylor, 2013).

The main attribute identified in the literature is uncertainty in making a decision, which O'Connor \& Jacobsen (2001) term as the "hallmark" of decisional conflict. A person will verbalize concern or distress as a result of the uncertainty felt about which alternative to select. Identifying defining attributes of this concept helps clarify it, and leads to the next steps of concept analysis: developing cases to more clearly illustrate the concept of decisional conflict. These cases are fictitious scenarios and do not include any individual's health care information.

\section{A Model Case}

A model case is an example of the concept where all the defining attributes are in place and accurately illustrates the concept in action (Walker \& Avant, 2005). In this model case, a 70 year old man who has had multiple occurrences of cancer has just been told by his oncologist that the cancer has recurred. The man had lymphoma 15 years ago and felt the chemotherapy itself almost killed him. Five years after that, he developed lung cancer. He was treated surgically, and also had chemotherapy and radiation. The treatments left him feeling weak and tired. He told his wife that if the 
cancer ever returned, he was going to refuse treatment. He was done with

chemotherapy, radiation, and surgeries. He had been through so much with his previous illnesses, and he did not think he had the strength to go through treatments again. Now he learns that he has lung cancer again. The patient is upset by the diagnosis, and initially states he does not want any treatment. The physician advises him to not decide too hastily. The physician is very encouraging and hopeful that with surgery, radiation and chemotherapy, the patient could be cancer-free once again and have many years to his life. The patient tells the oncologist he needs time to make his decision. The patient and his wife cry the entire drive home. Neither one knows what to do, but they know how miserable he was when undergoing chemotherapy. He tells her he has no idea what the right decision is, and is fed up with receiving this type of news. He is not ready to die. For weeks, he avoids any calls from family, friends, or even his physician. He can think of nothing else besides the looming decision. One minute he feels he should stick to his original decision to forego any treatment, but then the next minute, he feels hope the treatments could cure him. He loves being with his family and values them most above all else. He is stressed, and is feeling the effects physically. He feels his heart racing and experiences headaches, insomnia, and muscle tension. He repeatedly tells his wife he is uncertain about what to do. He is exhibiting the defining attributes in addition to the hallmark sign of decisional conflict, expressing uncertainty in which choice of action to take. 


\section{A Contrary Case}

A contrary case is an example of the opposite of the concept. None of the defining attributes are in place in the contrary case (Walker \& Avant, 2005). This contrary case presents an 88 year old retired nurse who worked many years in critical care. When asked by her primary care physician during a routine office visit if she knows her end of life wishes, she answers confidently that she does know her wishes and has documented these in her advance directives. Her son knows her wishes, has promised to abide by them and knows where all her important documents are stored. She has thought of her end-of-life plan carefully, explored all her options, and is confident in her decision. Her professional background makes her knowledgeable of all available options. She cared for her husband in their home until he passed away 10 years ago due to cancer. She knows that at end of life she wants to be cared for in the hospital or a palliative care facility and prefers to die a natural death with no medical intervention. She does not waver in her decision making. When death is imminent, she is still satisfied with her decision. Her son upholds her wishes, and she dies peacefully with her family around her.

\section{A Borderline Case}

A borderline case is an example of the concept that contains most of the defining attributes but not all of them, thus it is not a "pure" representation of the concept (Walker \& Avant, 2005). As an example of a borderline case, consider the case study of a 36 year old woman who must decide whether or not to have a thyroidectomy. The woman has several nodules on her thyroid and has undergone multiple fine needle 
aspiration biopsies with inconclusive results. The pathology report states the tissue was indeterminate for diagnosis. The surgeon suggests a lobectomy and possibly a total thyroidectomy. The other choice is to wait and watch. The woman is currently caring for her father who is dying of pancreatic cancer. She is married and has a son, and she does not want to leave her son motherless if she should have cancer. She works full time and is also enrolled in graduate studies. She is overwhelmed. She leaves the office to go home and discuss the matter with her husband. Her husband states he will support whichever decision she makes but feels the surgery is the safer of the two choices. The woman researches the diagnosis and options further. She vacillates between having the surgery or just waiting and watching for more symptoms. She decides to delay the decision for a week. Once the week is over, she knows she must face the decision. She feels it would be safer to remove the nodules and have a definitive diagnosis. She undergoes a left lobe thyroidectomy. The nodules are benign.

\section{Antecedents}

Antecedents are events or incidents which must happen prior to the concept's occurrence. The need to make a decision precedes decisional conflict, so in order to fully explore decisional conflict; we need to understand the process of decision making.

Decision making. Janis and Mann (1977) developed a Conflict-Theory Model of Decision-Making and noted that the process may result in decisional conflict. They purport this model can be applied to any decision-making situation that involves uncertainty and risk. 
They note that decision making involves exploring expectations and values.

Expectations include the anticipated consequences of the decision, and values are what the decision maker finds desirable. Some decisions will have unclear expectations or will have elements of good and bad in both alternatives and choices. This creates conflict in the decision making process. The decision maker considers basic questions about risks, consequences, alternatives and timeframe that relate to their approach to successful decision making. These questions reflect concerns about available information, losses, deadlines, and time pressures.

In addition to these antecedents, communication variables can also contribute to decisional conflict. Warnings, reassurances, and information can be presented to the decision maker by a number of methods such as mass media, private counselors, representatives, and healthcare personnel. Other antecedents include personality variables, predisposition characteristics, sensitivity to warnings, and previous exposure to similar crises (Janis \& Mann, 1977).

Janis \& Mann (1977) contend that people tend to utilize distinctive coping patterns to deal with decisions. Each coping pattern corresponds with a method of understanding or processing the information. This is not a one-size-fits-all process. According to Janis and Mann (1976), it is futile to attempt to identify one method of information processing and apply it to a variety of decision-making situations. Different tendencies in handling and making sense of information arise dependent upon the employed coping pattern. For instance, individuals who employ unconflicted adherence and unconflicted change coping patterns will not be interested in receiving all the 
available information, both positive and negative, to make an informed, methodological choice. As the term implies, they want to avoid conflict, so they will either stay with the status quo or go along with whatever avenue is suggested in order to maintain peace and tranquility. Individuals employing defensive avoidance will enjoy selective exposure to information. Individuals utilizing hyper vigilance will express extraordinary amounts of interest in all information regardless of the relevancy of the information. When individuals employ vigilance, they will display an open-mind and discriminate among information identified. In order to make an informed decision, one must employ vigilance (Umeh \& Omari-Asor, 2011).

Three antecedent conditions thought to determine or predict which coping patterns will be employed are awareness, hope, and belief. Janis and Mann (1976) stated if an individual was aware of the risks involved with the alternative choices, had hope that a better alternative existed, or believed there was enough time to research and decide, that person would employ a different coping mechanism than those without these conditions present. The individual with those three antecedents present would most likely employ a vigilant decision making style; conversely, an individual who was without those conditions might lean towards a defensive avoidance decision making style. In hyper-vigilance, the person experiences cognitive constriction and is unable to make a rational choice (Janis \& Mann, 1977).

Stress. Stress is often present in the place of decision making. Common causes of stress identified by Janis and Mann (1976) are too much information, inability to process all the information, social pressures, prejudice, ignorance, "information overload and 
the limitations of human information-processing, group pressures, blinding prejudice, ignorance, organizational constraints, and bureaucratic politics" (p. 657). Stress is not always a negative aspect of decision making. The right amount of stress is needed to make an adequate decision (Janis \& Mann, 1976). If stress is too low, motivation is lacking to thoroughly research all aspects of the decision. If stress is too high, the person is paralyzed and cannot research objectively to uncover adequate information to make an informed decision. Janis and Mann (1976) identify coping patterns of unconflicted adherence, unconflicted change, defensive avoidance, and hyper vigilance as forms of defective decision making especially in the case of critical decisions. In all cases aside from a decision requiring an immediate response, vigilance will usually lead to the highest quality decision making (Janis \& Mann, 1976). The presence or absence of awareness of the risks, hope that a better alternative is available, and belief that there is enough time to decide determine the coping pattern utilized. Intermediate levels of stress tend to result in vigilant decision making whereas the two extremes - very little and extreme stress will usually result in defective decision making (Janis \& Mann, 1976).

Personal characteristics. Some researchers suggest that factors that lead to decisional conflict can be divided between non-modifiable and modifiable factors. Nonmodifiable factors, such as gender, cannot be changed by the decision maker. Allen, Allen, Hilgeman and DeCoster (2008), found an association between female gender and higher decisional conflict, and a negative correlation between age and decisional conflict. 
Hispanic, Asian/Pacific Islanders and Latinos were more likely to experience decisional conflict than Black Americans and Caucasians in a study by Sudore et al. (2010). Greater decisional conflict was associated with having Alzheimer's disease, emphysema, and cognitive impairment (Yeakle \& Allen, 2007). Individuals, whose primary language was not English or spoke primarily Spanish, were associated with more uncertainty, $p<.001$. Health status, income, and literacy were other factors associated with uncertainty. Individuals with lower income and fair-to-poor health status, and limited literacy were associated with more uncertainty (Sudore et al., 2010). Modifiable factors include such things as lacking knowledge and expectations, clarity of values and support and resources (O'Connor \& Legare, 2012). Lack of experience in decision making or making decisions about a certain topic are also antecedents (Mcfarland \& Mcfarlane, 1989).

Lack of knowledge is a related concept that can lead to decisional conflict. When individuals lack knowledge, they may feel constrained and feel they do not have the resources available to make a proper decision. This could create much decisional conflict. Uncertainty is another related concept that is inherent in the decisional conflict analysis. Lack of experience in decision making is also related. If an individual has never had to make a healthcare decision, the person may feel ill-equipped to make the decision and experience decisional conflict.

\section{Consequences}

Consequences are events that occur as a result of the concept's occurrence

(Walker \& Avant, 2005). The expected outcome of decision making is that the person 
will make an effective informed decision (O'Connor, 1997). Decisional conflict leads to poor decision making (Pochon, Riis, Sanfey, Nystrom, \& Cohen, 2008). Janis and Mann (1976) identify anxiety as a reaction to making difficult decisions and presents with the following symptomology: agitation, a quick temper, sleeplessness, and appetite loss, tachycardia, pulse amplitude, and skin responses (p. 657). Post-decision regret is another consequence of decisional conflict. The amount of regret is dependent upon the degree the decision maker was able to employ vigilance (Janis \& Mann, 1977).

Stress can be both an antecedent and a result of decisional conflict. Fear of making a wrong choice can lead to stress. Mann, Burnett, Radford, and Ford (1997) contend that decisional conflict will result in psychological stress as a result of concerns about losing personal, material, and/or social status such as losing one's reputation and self-esteem, an assertion also espoused by Janis and Mann (1976).

Additional consequences of decisional conflict include hesitation, vacillation, feelings of uncertainty and distress (Janis \& Mann, 1976). Janis used the example of a political leader who experienced symptoms of tension following a decision. The political leader became ineffective and less likely to follow through on implementing decisions. Stress as a result of decisional conflict leads to failure in quality decision making (Janis \& Mann, 1976). 
Table 1-1

Defining Attributes, Antecedents, and Consequences

\begin{tabular}{|c|c|c|}
\hline Defining Attributes & Antecedents & Consequences \\
\hline $\begin{array}{l}\text { Verbalized uncertainty, } \\
\text { Concern over negative } \\
\text { outcomes, } \\
\text { Questioning moral } \\
\text { principles, personal } \\
\text { values and beliefs, } \\
\text { Verbalizing undesired } \\
\text { consequences of } \\
\text { alternative actions, } \\
\text { Wavering between } \\
\text { choices, Delayed } \\
\text { decision-making, } \\
\text { Preoccupation with } \\
\text { decision-making, } \\
\text { Self-focusing } \\
\text { Interfering in decision } \\
\text { making, Physical signs of } \\
\text { distress: } \\
\text { 1) Tachycardia } \\
\text { 2) muscle tension } \\
\text { 3) restlessness } \\
\text { Stress }\end{array}$ & $\begin{array}{l}\text { Serious risks } \\
\text { No hope of way out } \\
\text { Insufficient time to search } \\
\text { and deliberate the decision } \\
\text { Very little and extreme } \\
\text { stress } \\
\text { Anticipated consequences } \\
\text { Anticipated approval or } \\
\text { disapproval of stakeholders } \\
\text { Self-reactions guided by } \\
\text { moral standards and values } \\
\text { No acceptable options exist } \\
\text { Stress }\end{array}$ & $\begin{array}{l}\text { Anxiety } \\
\text { Symptomology: } \\
\text { 1) Agitation } \\
\text { 2) quick temper } \\
\text { 3) Sleeplessness } \\
\text { 4) appetite loss } \\
\text { 5) Tachycardia } \\
\text { 6) pulse amplitude } \\
\text { 7) skin responses } \\
\text { Post-decision regret } \\
\text { Poor decision making } \\
\text { Stress }\end{array}$ \\
\hline
\end{tabular}

\section{Empirical Referents}

Walker and Avant (2005) state that determining the empirical referents for defining attributes are the final step in a concept analysis. Empirical referents are those classes or categories of phenomena that exist and demonstrate the presence of the 
concept. These are used to develop instruments to measure the concept. The salient indicator of decisional conflict is the individual expressing uncertainty. Specific to decisional conflict, the Decisional Conflict Scale is a valid and reliable tool to measure the concept. The scale has a test-re-test reliability coefficient of 0.81 and high internal consistency demonstrated by Cronbach's alpha ranging from 0.78 to 0.92 for the total scale (Dales et al., 1999; Allen et al., 2008; Legare, O’Connor, Graham, Wells, \& Tremblay, 2006; Kryworuchko, Stacey, Bennett, \& Graham, 2008). Face, content, construct, and predictive validity have been demonstrated (Lyon et al., 2009).

O'Connor (1995) developed the Decisional Conflict Scale to measure the efficacy of decision aids in decreasing decisional conflict. The Ottawa Decision Support Framework provided the conceptual framework for the Decisional Conflict Scale (O'Connor, 1995). There are several versions of the Decisional Conflict Scale, but the one most commonly used is a 16 -item questionnaire with a 5-point Likert scale with responses ranging from "Strongly Agree" to "Strongly Disagree;" higher scores indicate higher decisional conflict (O'Connor, 1993). The instrument has been widely used on various populations, including adults and families. This tool is comprehensive because it explores more than the decision-making process, it also measures the quality of the decision.

\section{Conclusion}

Janis and Mann (1976) were the first to explore the concept of decisional conflict which can be a result of decision making. Definitions evolved in a number of disciplines and share elements of the concept. A model case, contrary case, and borderline case 
were presented to more clearly differentiate the concept of decisional conflict. Antecedents of decisional conflict include lack of knowledge, anticipated consequences of the decision, anticipated approval or disapproval of key stakeholders, and selfreactions guided by the individual's moral standards and values. O'Connor and Jacobsen (2001) termed uncertainty in making a decision as the "hallmark" of decisional conflict (p. 8). Experiencing this main attribute, a person will verbalize concern or distress as a result of the uncertainty felt about which alternative to select. The key assessment findings in someone experiencing decisional conflict are verbalizing feelings of uncertainty, undesired consequences, hesitation, vacillation between choices, verbalization and showing physical signs of distress such as muscle tension, restlessness and tachycardia, questioning values and beliefs, and delaying decision making (O'Connor, 1997). 


\section{References}

Allen, R.S., Allen, J.Y., Hilgeman, M.M. \& DeCoster, J. (2008). End-of-life decision-making, decisional conflict and enhanced information: Race effects. Journal of American Geriatric Society, 56, 1904-1909

Conflict (n.d.). In Merriam-Webster online dictionary. Retrieved October 15, 2013, from http://www.merriam-webster.com/dictionary/conflict

Dales, R.E., O’Connor, A., Hebert, P., Sullivan, K., McKim, \& Llewellyn-Thomas, H. (1999). Intubation and mechanical ventilation for COPD*: Development of an instrument to elicit patient preference. CHEST, 116, 792-800.

Decision (n.d.). In Merriam-Webster online dictionary. Retrieved October 15, 2013, from http://www.merriam-webster.com/dictionary/decision

Hiltunen, E.F., Chase, S.K., \& Medich, C. (1999). Decisional conflict in families making end of life treatment decisions. In Classification of nursing diagnoses:

Proceedings of the thirteenth conference. North American Nursing Diagnosis Association. (Ed by Rantz and LeMone). Cinahl Information Systems.

Janis, I.L. (1959). Decisional conflict: A theoretical analysis. The Journal of Conflict Resolution, 3, 6-27.

Janis, I.L. \& Mann, L. (November-December, 1976). Coping with decisional conflict: An analysis of how stress affects decision-making suggests interventions to improve the process. American Scientist, 64, 657-667. Retrieved from http://www.jstor.org/stable/27847557 DOI 10.2307/27847557.

Janis, I.L. \& Mann, L. (1977). Decision making: A psychological analysis of conflict, choice, and commitment. New York: The Free Press.

Kryworuchko, J. Stacey, D., Bennett, C., \& Graham, I.D. (2008). Appraisal of primary outcome measures used in trials of patient decision support. Patient Education \& Counseling. 73, 497-503. Doi: 10.1016/j.pec.22008.07.011

Legare, F., O'Connor, A.M., Graham, I.D., Wells, G.A., \& Tremblay, S. (2006). Impact of the Ottawa Decision Support framework on the agreement and the difference between patients' and physicians' decisional conflict. Medical Decision Making, 375-390.

Lyon, M.E., Garvie, P.A., McCarter, R., Briggs, L., He, J., \& DAngelo, L.J., (2009). Who will speak for me? Improving end-of-life decision-making for adolescents with HIV and their families. Pediatrics, 123, 199-206.

Mann, L. Burnett, P., Radford, M., \& Ford, S. (1997). The Melbourne decision making questionnaire: An instrument for measuring patterns for coping with decisional conflict. Journal of Behavioral Decision Making, 10, 1-19.

O'Connor, A. (1995). Validation of a decisional conflict scale. Medical Decision Making, 15, 25-30.

O'Connor, A. (1997). Decisional conflict. In G.K. McFarland and E.A. McFarlane (Eds.). Nursing diagnosis and intervention ( $3^{\text {rd }}$ ed. Pp. 486-496). Toronto, Canada: Mosby. 
O'Connor, A., Tugwell, P., Wells, G.A., Elmslie, T., Jolly, E., Hollingworth, G....Drake, E. (1998). A decision aid for women considering hormone therapy after menopause: Decision support framework and evaluation. Patient Education and Counseling, 33, 267-279.

O'Connor, A. \& Legare, F. (2012). Decisional conflict. Retrieved from http://thehealthscience.com/wiki/Decisional-Conflict.

Pochon, J.B., Riis, J., Sanfey, A.G., Nystrom, L.E., \& Cohen, J.D. (2008). Functional imaging of decision conflict. Journal of Neuroscience, 28, 3468-3473. doi: 10.1523/JNEUROSCI.4195-07.2008.

Ralph, S. S., \& Taylor, C. M. (2013). Nursing diagnosis reference manual (9th ed.). Philadelphia: Wolters Kluwer Health/Lippincott Williams \& Wilkins.

Sudore, R.L., Schillinger, D., Knight, S.J. \& Fried, T.R. (2010). Uncertainty about advance care planning treatment preferences among diverse older adults. Journal of Health Communication, 15, 159-171.

The American Heritage Dictionary of the English Language, (2000). (4 ${ }^{\text {th }}$ ed.). Houghton Mifflin Company. Retrieved on November 8, 2004 from http://www.dictionary.reference.com.

Tsakraklides, S. (2011). Grid Enabled Measures Database. Retrieved from https://www.gem-beta.org/public/ConstructDetail.aspx?cid=1061

Turk, M.A., (2009). Health, mortality, and wellness issues in adults with cerebral palsy. Development Medicine \& Child Neurology, 51, 24-29.

Umeh, K. \& Omari-Asor, L. (2011). Emotional vulnerability and coping styles for resolving decisional conflict. The Journal of Psychology, 145, 297-312.

Walker, L.O., \& Avant, K.C. (2005). Strategies for theory construction in nursing. (4 ${ }^{\text {th }}$ ed.). Upper Saddle River, N.J.: Pearson Prentice Hall.

Yeakle, J. \& Allen, R. (2007). Piloting EDMAC: The end-of-life decision making and memory complaint project. University of Alabama Mcnair Journal, 7, 195-215. 
CHAPTER ॥

A SYSTEMATIC REVIEW: PERSONAL CHARACTERISTICS AND LEARNING PREFERENCES

IN END-OF-LIFE DECISION MAKING

\begin{abstract}
This purpose of this systematic review was to evaluate the end-of-life decision making (EOL DM) literature and identify factors associated with decisional conflict (DC) and preferences for type of decision aid (DA). Studies reviewed included primary studies of participants older than 18, published in English between 1998-2013, focusing on factors associated with DC, DAs assisting with EOL DM, or factors influencing preferences for type of DAs to assist learning about EOL options. Exclusion criteria included pediatric studies, EOL research not dealing with DM or DC.

The review resulted in 14 studies; participants were a mean age of 60. Data was abstracted and articles were rated for quality utilizing the Johns Hopkins Nursing Evidence Based Practice Research Evidence Appraisal Tool (Dearholt \& Dang, 2012). Three studies rated "good"; six studies rated "high", 3 rated "good" and 5 rated "low" in quality. Personal characteristics associated with DC are Hispanic, Latino, or Asian/Pacific Islander race, older age, and limited health literacy (Sudore et al., 2010; Volandes et al., 2010). Participants, older than 60, preferred fewer learning methods, while women and
\end{abstract}


those with higher education favored a variety of methods (Chelf et al., 2002). End-of-life DM is enhanced through DAs. Decision aids show promise in EOL DM, but preferences for type of DA are unclear. Educating patients is an integral part of nursing and best practice includes utilizing preferred learning methods. 
Decisions about end of life (EOL) care are among the most difficult decisions people face, especially when they have poor understanding of life-sustaining treatments. Making EOL decisions without sufficient information frequently leads to feelings of uncertainty, which is a primary characteristic of decisional conflict (DC). Decisional conflict refers to uncertainty about which action to take (O'Connor, 1993). Health care workers need more effective ways to educate individuals (Porensky \& Carpenter, 2008). Decision aids (DA) can increase peoples' knowledge and understanding of EOL options. The preferred mode of DA to foster learning is unclear. Identifying personal characteristics and factors associated with DC and preferred mode of DA can assist in EOL decision making (DM).

Educating patients, an integral part of nursing, succeeds best when the education method aligns with learning preferences. Learning about options at EOL is stressful. Poor communication often exists between patients and physicians regarding EOL (Janssen, Spruit, Schols \& Emiel, 2010). Edwards and Elwyn (2001) described EOL discussions as one sided rushed speeches by physicians that do not effectively educate patients. Marbach and Griffie (2011) found that verbal discussions are not enough. Patients are sometimes too overwhelmed during conversations with their health care provider to retain and process the information they just received. Many desire resources they can take home and read independently, so they can learn the information at their own pace. The rise of consumerism in health care supports people taking control of their own health care needs rather than leaving decisions to their physicians. 
In a study of patients with chronic kidney disease, Davison (2010) found that $80 \%$ or more wish to be informed about EOL treatment options, felt it was important to be prepared, plan ahead and participate in DM. However, $61 \%$ of participants regretted their decision to start dialysis (Davison, 2010). Better DM support before starting dialysis may have led to fewer regrets. Decision aids show promise in improving people's DM, but EOL DM is particularly sensitive. Although there is a large body of research exploring decision aids, studying decision aids with EOL DM is still underdeveloped. The purpose of this systematic review is to explore literature focusing on factors associated with decisional conflict and factors associated with preferences for type of decision aid to assist learning about EOL DM.

\section{Methods}

\section{Search Strategy}

This systematic review included a search of the following databases: Cumulative Index to Nursing and Allied Health Literature (CINAHL), PubMed, Google Scholar, PsychInfo and Medline for key terms: decisional conflict, decision-making, end of life, knowledge, life-sustaining treatments, patient education, preference for learning, and technology-based decision aids. These key terms were then each combined with the key term "end of life" with the Boolean phrase "and" to capture those references that pertained to the EOL DM literature. Reference lists of pertinent articles were explored as well as searching for notable authors' manuscripts. The literature search was guided by these research questions: 
a) What patient characteristics are associated with decisional conflict about EOL DM in chronically ill elders?

b) What patient characteristics are associated with preferences for type of decision aid to assist learning about EOL care in chronically ill elders?

Inclusion criteria. The inclusion criteria for this review were primary studies of adult participants older than 18, research dating from 1998 to 2013, studies exploring the concepts of decisional conflict, factors associated with DC, decision aid assisting with EOL DM, or factors influencing preferences for type of DAs in EOL. Exclusion criteria included pediatric research, EOL research that did not deal with DM or DC, and DM or DA research that did not deal with EOL. Also excluded were systematic reviews, reviews of literature, and integrative reviews.

\section{Results}

The search produced 2800 studies. Reviewing the titles and abstracts eliminated nonpertinent $(n=1831)$, studies with exclusion requirements $(n=280)$, and duplicate studies ( $n=566$ ) bringing the total to 123 articles. Abstracts of potential studies were then read for inclusion criteria. Finally, the full articles were read and reread to determine qualification for inclusion based on inclusion and exclusion criteria. The final sample included 14 studies. The studies included 2612 participants from the United States, Canada, Australia and Taiwan. 


\section{Designs of Studies}

The literature in this review includes 14 quantitative studies with the following research designs: two descriptive, exploratory studies; 10 quasi-experimental studies; two randomized control trials.

\section{Description of Studies}

Table 1 summarizes characteristics and key findings of the 14 studies reviewed. The two descriptive, exploratory studies examined learning preferences (Chelf et al., 2002) and EOL care preferences (Davison, 2010). Researchers looked at effects of a variety of DAs including print media with discussion (Tung et al., 2011), scenarios (Allen et al., 2008; Sudore et al., 2010; Yeakle \& Allen, 2007), audio booklets (Leighl et al., 2011; Mitchell et al., 2001; Wilson et al., 2005), multimedia DVD with follow-up discussion (Chiou \& Chung, 2011) webinar with still images (Reinke et al., 2011) and videos (El-Jawahri et al., 2010; Volandes et al., 2010). Outcomes included knowledge, uncertainty, EOL care preferences, decision aid preferences, decisional conflict, decisional stability, decisional regret, understanding and completion of advanced directives. Volandes, Barry, Chang \& Paasche-Orlow, (2010) investigated whether health literacy and knowledge had an impact on uncertainty regarding EOL care decisions. Allen, Allen, Hilgeman and DeCoster (2008) investigated associations between literacy and race, learning preferences, and perceptions of the EOL experience in the hospital. Chiou and Chung, (2011) looked at the effect of a multimedia decision aid on knowledge, uncertainty and decision regret in a group of people with end-stage renal disease. Tung et al. (2011) completed a retrospective analysis. Yeakle and Allen (2007) 
sought to determine the impact information has on life-sustaining treatment decisions of healthy older adults and those with memory complaints. Others explored effects of information on EOL DM using various DAs such as video In the two randomized control trials, researchers sought to assist individuals through EOL DM with specific DAs (EIJawahri et al., 2010; Leighl et al., 2011). 
Table 2-1

Summary Table of Reviewed Studies

\begin{tabular}{l|l|l|l|l|l|l|l}
\hline Authors & $\begin{array}{l}\text { Study } \\
\text { Objective }\end{array}$ & Design & $\begin{array}{l}\text { Intervention } \\
\text { (Decision } \\
\text { Aid) }\end{array}$ & Outcomes & Instrument & Key Findings \\
\hline $\begin{array}{l}\text { Chelf et } \\
\text { al. (2002) }\end{array}$ & $\begin{array}{l}\text { Identify } \\
\text { content items } \\
\text { for education } \\
\text { for patients } \\
\text { with cancer. } \\
\text { Assess learning } \\
\text { preferences. }\end{array}$ & $\begin{array}{l}\text { Descriptive, } \\
\text { exploratory }\end{array}$ & None & $\begin{array}{l}\text { Preference for } \\
\text { learning }\end{array}$ & $\begin{array}{l}\text { Author made } \\
\text { questionnaire } \\
\text { (37-item) }\end{array}$ & $\begin{array}{l}\text { Preferred DA: discussion } \\
\text { (HCP, patients), print } \\
\text { (booklet, brochure). Little } \\
\text { interest in computer } \\
\text { assisted learning. Women } \\
\text { prefer variety of options. }\end{array}$ & $\begin{array}{l}\text { Good } \\
\text { prem }\end{array}$ \\
\hline $\begin{array}{l}\text { Davison, } \\
\text { (2010) }\end{array}$ & $\begin{array}{l}\text { Evaluate EOL } \\
\text { care } \\
\text { preferences of } \\
\text { patients with } \\
\text { chronic kidney } \\
\text { disease }\end{array}$ & $\begin{array}{l}\text { Descriptive, } \\
\text { exploratory }\end{array}$ & None & $\begin{array}{l}\text { Knowledge } \\
\text { EOL care } \\
\text { preferences } \\
\text { Uncertainty }\end{array}$ & Questionnaire & $\begin{array}{l}\text { Preferred DA: discussion } \\
\text { (HCP, friends), print, } \\
\text { computer, TV }\end{array}$ & High \\
\hline $\begin{array}{l}\text { Sudore et } \\
\text { al. (2010) }\end{array}$ & $\begin{array}{l}\text { Assess } \\
\text { uncertainty } \\
\text { about } \\
\text { treatment } \\
\text { preferences } \\
\text { after reading a } \\
\text { booklet with } \\
\text { scenarios }\end{array}$ & $\begin{array}{l}\text { Single } \\
\text { group, post- } \\
\text { test }\end{array}$ & Scenarios & Uncertainty & $\begin{array}{l}\text { "How certain are } \\
\text { you about your } \\
\text { decision?" } \\
\text { TOFHLA }\end{array}$ & $\begin{array}{l}\text { Differences in health } \\
\text { literacy among racial } \\
\text { groups, }\end{array}$ & Health Literacy \\
\end{tabular}




\begin{tabular}{|c|c|c|c|c|c|c|c|}
\hline $\begin{array}{l}\text { Dales et } \\
\text { al. (1999) }\end{array}$ & $\begin{array}{l}\text { Development } \\
\text { and evaluation } \\
\text { of DA }\end{array}$ & $\begin{array}{l}\text { Single } \\
\text { group, pre- } \\
\text { and post- } \\
\text { test }\end{array}$ & $\begin{array}{l}\text { Audio } \\
\text { booklet }\end{array}$ & $\begin{array}{l}\text { Preferences for } \\
\text { mechanical } \\
\text { ventilation } \\
\text { Decisional } \\
\text { Conflict } \\
\text { Decisional } \\
\text { Stability }\end{array}$ & $\begin{array}{l}\text { Questionnaire } \\
\text { DCS (16 item) } \\
\text { Interview after } 1 \\
\text { year }\end{array}$ & $\begin{array}{l}\text { Low decisional conflict } \\
\text { after Audio booklet DA on } \\
\text { intubation and mechanical } \\
\text { ventilation }\end{array}$ & Low \\
\hline $\begin{array}{l}\text { Mitchell } \\
\text { et al. } \\
(2001)\end{array}$ & $\begin{array}{l}\text { Development } \\
\text { and evaluation } \\
\text { of DA for tube } \\
\text { feedings for } \\
\text { cognitively } \\
\text { impaired }\end{array}$ & $\begin{array}{l}\text { Single } \\
\text { group, pre- } \\
\text { and post- } \\
\text { test }\end{array}$ & $\begin{array}{l}\text { Audio } \\
\text { booklet }\end{array}$ & $\begin{array}{l}\text { Knowledge } \\
\text { Predisposition } \\
\text { to options } \\
\text { Decisional } \\
\text { conflict } \\
\text { Acceptability of } \\
\text { DA }\end{array}$ & $\begin{array}{l}\text { Questionnaire } \\
\text { 11-item leaning } \\
\text { scale } \\
\text { DCS } \\
\text { Questionnaire }\end{array}$ & $\begin{array}{l}\text { Low decisional conflict } \\
\text { after Audio booklet DA. } \\
\text { DA influenced those who } \\
\text { were unsure }\end{array}$ & Low \\
\hline $\begin{array}{l}\text { Reinke et } \\
\text { al. (2011) }\end{array}$ & $\begin{array}{l}\text { Assess } \\
\text { feasibility of } \\
\text { using a } \\
\text { webinar to } \\
\text { coach patients } \\
\text { with COPD on } \\
\text { EOL } \\
\text { communication }\end{array}$ & $\begin{array}{l}\text { Single } \\
\text { group, pre- } \\
\text { and post- } \\
\text { test }\end{array}$ & $\begin{array}{l}\text { Webinar } \\
\text { with still } \\
\text { images }\end{array}$ & $\begin{array}{l}\text { EOL knowledge } \\
\text { and attitudes }\end{array}$ & $\begin{array}{l}\text { Author made } \\
\text { questionnaire }\end{array}$ & $\begin{array}{l}\text { Webinar was easy to } \\
\text { use, but all desired a } \\
\text { video stream instead of } \\
\text { still shots }\end{array}$ & Low \\
\hline
\end{tabular}




\begin{tabular}{|c|c|c|c|c|c|c|c|}
\hline $\begin{array}{l}\text { Volandes } \\
\text { et al. } \\
(2010)\end{array}$ & $\begin{array}{l}\text { Assess if DA } \\
\text { could improve } \\
\text { decision } \\
\text { making }\end{array}$ & $\begin{array}{l}\text { Single } \\
\text { group, pre- } \\
\text { and post- } \\
\text { test }\end{array}$ & Video & $\begin{array}{l}\text { Health Literacy } \\
\text { Uncertainty }\end{array}$ & $\begin{array}{l}\text { Rapid Estimate } \\
\text { of Adult Literacy } \\
\text { in Medicine. } \\
\text { Health literacy } \\
\text { DCS, } \\
\text { Uncertainty } \\
\text { subscale }\end{array}$ & $\begin{array}{l}\text { Lower uncertainty after } \\
\text { video DA. Those with } \\
\text { limited health literacy had } \\
\text { more uncertainty }\end{array}$ & High \\
\hline $\begin{array}{l}\text { Wilson et } \\
\text { al. (2005) }\end{array}$ & $\begin{array}{l}\text { Evaluation of } \\
\text { DA }\end{array}$ & $\begin{array}{l}\text { Single } \\
\text { group, pre- } \\
\text { and post- } \\
\text { test }\end{array}$ & $\begin{array}{l}\text { Audio } \\
\text { booklet }\end{array}$ & $\begin{array}{l}\text { Dyspnea } \\
\text { Health } \\
\text { Depression } \\
\text { Decisional } \\
\text { Conflict }\end{array}$ & $\begin{array}{l}\text { Baseline } \\
\text { Dyspnea Index } \\
\text { SF-36 } \\
\text { Beck Depression } \\
\text { Inventory } \\
\text { DCS }\end{array}$ & $\begin{array}{l}\text { Decrease in decisional } \\
\text { conflict after DA }\end{array}$ & Low \\
\hline $\begin{array}{l}\text { Yeakle \& } \\
\text { Allen } \\
(2007)\end{array}$ & $\begin{array}{l}\text { Assessed } \\
\text { impact of DA } \\
\text { on treatment } \\
\text { choices and } \\
\text { explored } \\
\text { relations of } \\
\text { memory } \\
\text { complaint, } \\
\text { depression, } \\
\text { and decisional } \\
\text { conflict to } \\
\text { EOL decision } \\
\text { making }\end{array}$ & $\begin{array}{l}\text { Two group, } \\
\text { Pre/post }\end{array}$ & $\begin{array}{l}\text { Scenarios } \\
\text { (LSPQ) }\end{array}$ & $\begin{array}{l}\text { Subjective } \\
\text { Health } \\
\text { Cognitive Status } \\
\text { Depression } \\
\text { Memory } \\
\text { Decisional }\end{array}$ & $\begin{array}{l}\text { Three questions } \\
\text { Telephone } \\
\text { Interview for } \\
\text { Cognitive Status } \\
\text { - modified } \\
\text { Center for } \\
\text { Epidemiological } \\
\text { Studies } \\
\text { Depression Scale } \\
\text { Metamemory in } \\
\text { Adulthood } \\
\text { Questionnaire }\end{array}$ & $\begin{array}{l}\text { Greater decisional conflict } \\
\text { was associated with } \\
\text { cognitive impairment and } \\
\text { less desire for life } \\
\text { sustaining treatment. } \\
\text { Experimental group } \\
\text { (received more } \\
\text { information) had more } \\
\text { decisional conflict }\end{array}$ & Low \\
\hline
\end{tabular}




\begin{tabular}{|c|c|c|c|c|c|c|c|}
\hline & & & & $\begin{array}{l}\text { Conflict } \\
\text { Life-Support } \\
\text { Preferences }\end{array}$ & $\begin{array}{l}\text { DCS (10-item, } 3 \\
\text { response } \\
\text { categories) } \\
\text { Life-Support } \\
\text { Preferences/Pre } \\
\text { dictions } \\
\text { Questionnaire } \\
\text { (modified, 3/9 } \\
\text { scenarios } \\
\text { utilized) }\end{array}$ & & \\
\hline $\begin{array}{l}\text { Allen et } \\
\text { al. (2008) }\end{array}$ & $\begin{array}{l}\text { Examine } \\
\text { effects of DA } \\
\text { on EOL } \\
\text { decision } \\
\text { making }\end{array}$ & $\begin{array}{l}\text { Two group, } \\
\text { post test }\end{array}$ & $\begin{array}{l}\text { Scenarios } \\
\text { (LSPQ) }\end{array}$ & $\begin{array}{l}\text { Life-Support } \\
\text { Preferences } \\
\text { Decisional } \\
\text { conflict }\end{array}$ & $\begin{array}{l}\text { Life-Support } \\
\text { Preferences/Pre } \\
\text { dictions } \\
\text { Questionnaire } \\
\text { (modified, 3/9 } \\
\text { scenarios } \\
\text { utilized) } \\
\text { DCS (10-item, } 3 \\
\text { response } \\
\text { categories) }\end{array}$ & $\begin{array}{l}\text { Significantly less } \\
\text { decisional conflict in } \\
\text { group with more } \\
\text { information }\end{array}$ & High \\
\hline $\begin{array}{l}\text { Chiou, \& } \\
\text { Chung } \\
(2011)\end{array}$ & $\begin{array}{l}\text { Assessed DA } \\
\text { effects on } \\
\text { knowledge, } \\
\text { decision } \\
\text { making and } \\
\text { uncertainty }\end{array}$ & $\begin{array}{l}\text { Two group, } \\
\text { pre- and } \\
\text { post-test }\end{array}$ & $\begin{array}{l}\text { Multimedia } \\
\text { DVD } \\
\text { (audio, } \\
\text { video, 3-D } \\
\text { animation) }\end{array}$ & $\begin{array}{l}\text { Knowledge } \\
\text { Uncertainty } \\
\text { Decision regret }\end{array}$ & $\begin{array}{l}\text { Knowledge scale } \\
\text { Uncertainty } \\
\text { scale } \\
\text { Decision making } \\
\text { regret scale - }\end{array}$ & $\begin{array}{l}\text { Decision regret higher in } \\
\text { control group }\end{array}$ & High \\
\hline
\end{tabular}




\begin{tabular}{|c|c|c|c|c|c|c|c|}
\hline & & & $\begin{array}{l}\text { and } \\
\text { telephone } \\
\text { follow-up }\end{array}$ & & Chinese version & & \\
\hline $\begin{array}{l}\text { El- } \\
\text { Jawahri, } \\
\text { et al. } \\
(2010)\end{array}$ & $\begin{array}{l}\text { Determine if } \\
\text { DA can } \\
\text { improve } \\
\text { decision } \\
\text { making. }\end{array}$ & $\mathrm{RCT}$ & $\begin{array}{l}\text { Video and } \\
\text { Discussion }\end{array}$ & $\begin{array}{l}\text { Goals of care } \\
\text { Comfort with } \\
\text { video } \\
\text { DM uncertainty } \\
\text { EOL treatment } \\
\text { knowledge }\end{array}$ & $\begin{array}{l}\text { Questionnaire } \\
\text { Questionnaire } \\
\text { DCS (__ subset) } \\
\text { Questionnaire }\end{array}$ & $\begin{array}{l}\text { Increased comfort and } \\
\text { less uncertainty in those } \\
\text { viewing video DA }\end{array}$ & High \\
\hline $\begin{array}{l}\text { Leighl et } \\
\text { al. (2011) }\end{array}$ & $\begin{array}{l}\text { Determine } \\
\text { impact of DA } \\
\text { on knowledge, } \\
\text { treatment } \\
\text { decisions, DC, } \\
\text { decision } \\
\text { making, } \\
\text { consultation } \\
\text { satisfaction, } \\
\text { anxiety and } \\
\text { quality of life. }\end{array}$ & RCT & $\begin{array}{l}\text { Audio } \\
\text { booklet }\end{array}$ & $\begin{array}{l}\text { Anxiety } \\
\text { Information } \\
\text { preferences } \\
\text { Decision } \\
\text { involvement } \\
\text { preference } \\
\text { Understanding } \\
\text { Consultation } \\
\text { satisfaction } \\
\text { Decisional } \\
\text { Conflict } \\
\text { Decision } \\
\text { Satisfaction }\end{array}$ & $\begin{array}{l}\text { State-Trait } \\
\text { Anxiety } \\
\text { Inventory } \\
\text { Cassileth } \\
\text { Information } \\
\text { Styles Scale } \\
\text { Control } \\
\text { Preferences } \\
\text { Scale } \\
\\
\text { Questionnaire } \\
\text { Satisfaction with } \\
\text { Consultation } \\
\text { DCS } \\
\text { Satisfaction with } \\
\text { Decision Scale }\end{array}$ & $\begin{array}{l}\text { Decisional conflict } \\
\text { unrelated to decision aid, } \\
\text { anxiety, age or gender. } \\
\text { No difference between } \\
\text { groups in decision } \\
\text { satisfaction or decisional } \\
\text { conflict }\end{array}$ & Good \\
\hline
\end{tabular}




\begin{tabular}{l|l|l|l|l|l|l|l}
\hline $\begin{array}{l}\text { Tung et } \\
\text { al. (2011) }\end{array}$ & $\begin{array}{l}\text { Determine if } \\
\text { DA would } \\
\text { increase } \\
\text { knowledge and } \\
\text { AMD } \\
\text { completion. }\end{array}$ & $\begin{array}{l}\text { Two group, } \\
\text { pre/post }\end{array}$ & $\begin{array}{l}\text { Written } \\
\text { materials } \\
\text { and } \\
\text { Discussion }\end{array}$ & $\begin{array}{l}\text { Advance } \\
\text { directive } \\
\text { completion } \\
\text { Preference for } \\
\text { type of } \\
\text { educational } \\
\text { material }\end{array}$ & $\begin{array}{l}\text { Number } \\
\text { completed }\end{array}$ & Questionnaire & \\
& & & & \\
\hline
\end{tabular}




\section{Sample}

The samples in these studies were somewhat homogenous. The mean age for the participants was 60 , and they were a mostly white, somewhat educated group of individuals, which limits generalizability to the population as a whole. Table 2 summarizes study sample demographics. Over half of the studies took place in the U.S. $(n=8)$, four in Canada, one study had participants from both Canada and Australia and one was from Taiwan. Twelve of the studies included participants who were recruited from a healthcare facility: primary care, pulmonary rehabilitation or dialysis, and two studies recruited participants from the community. Of the eight studies that included race demographics, on average $65 \%$ of participants were White, $26 \%$ were Black and only one study listed Hispanic participants. Ten studies listed education level, and most participants had either some high school education or higher degrees. Eight studies described marital status, with most participants noting married or widowed. Researchers studied patients with chronic obstructive pulmonary disease, end-stage renal disease, dementia, or cancer. Few studies described participants' health status, health literacy or income. 
Table 2-2

Sample Demographics

\begin{tabular}{|c|c|c|c|c|c|c|c|}
\hline Authors & $\mathrm{N}$ & $\begin{array}{l}\text { Mean } \\
\text { Age }\end{array}$ & $\begin{array}{c}\text { Study } \\
\text { Location }\end{array}$ & Gender & Race & Education & Disease \\
\hline $\begin{array}{l}\text { Chelf et al. } \\
(2002)\end{array}$ & 625 & 64 & USA & $\begin{array}{l}43 \% \mathrm{M} ; 54 \% \mathrm{~F} \\
4 \% \text { unknown }\end{array}$ & $N / A$ & $\begin{array}{l}54 \%>\mathrm{HS} \\
43 \% \leq \mathrm{HS}\end{array}$ & Cancer \\
\hline Davison, (2010) & 584 & 68 & Canada & $54 \% \mathrm{M} ; 46 \% \mathrm{~F}$ & $\begin{array}{l}\text { 80\% White, 7\% } \\
\text { Aboriginal 8\% } \\
\text { Asian }\end{array}$ & $\begin{array}{l}66 \%>\mathrm{HS} \\
31.5 \%<\mathrm{HS}\end{array}$ & $\begin{array}{l}\text { Chronic Kidney } \\
\text { Disease }\end{array}$ \\
\hline $\begin{array}{l}\text { Sudore et al. } \\
(2010)\end{array}$ & 205 & 61 & USA & $47 \% \mathrm{M} ; 53 \% \mathrm{~F}$ & $\begin{array}{l}\text { 25\% White } 31 \% \\
\text { Hispanic } 24 \% \\
\text { Black } \\
9 \% \text { Asian } \\
\text { 10\% Multi-racial }\end{array}$ & $32 \%<\mathrm{HS}$ & $\mathrm{N} / \mathrm{A}$ \\
\hline $\begin{array}{l}\text { Dales et al. } \\
\text { (1999) }\end{array}$ & 20 & 66 & Canada & $50 \% \mathrm{M} ; 50 \% \mathrm{~F}$ & N/A & $\mathrm{N} / \mathrm{A}$ & COPD \\
\hline $\begin{array}{l}\text { Mitchell et al. } \\
\text { (2001) }\end{array}$ & 15 & 56 & Canada & $73 \% \mathrm{~F}$ & N/A & $\mathrm{N} / \mathrm{A}$ & Dementia \\
\hline $\begin{array}{l}\text { Reinke et al. } \\
\text { (2011) }\end{array}$ & 7 & 68 & USA & $43 \% \mathrm{~F}$ & $\begin{array}{l}85 \% \text { White } \\
15 \% \text { Black }\end{array}$ & $\begin{array}{l}57 \% \geq \text { college } \\
\text { level }\end{array}$ & COPD \\
\hline
\end{tabular}




\begin{tabular}{|c|c|c|c|c|c|c|c|}
\hline $\begin{array}{l}\text { Volandes et al. } \\
\text { (2010) }\end{array}$ & 146 & 57 & USA & $64 \% \mathrm{~F}$ & $\begin{array}{l}56 \% \text { Black; } 44 \% \\
\text { White }\end{array}$ & $\begin{array}{l}56 \% \text { HS or less } \\
44 \% \geq \text { College }\end{array}$ & Dementia \\
\hline $\begin{array}{l}\text { Wilson et al. } \\
\text { (2005) }\end{array}$ & 33 & $\begin{array}{l}\text { No } \\
\text { MV: } \\
71 \\
\text { MV: } \\
62\end{array}$ & & $\begin{array}{l}\text { No MV: } \\
65 \% \text { M; 35\% F } \\
\text { MV: 30\% M; 70\% F }\end{array}$ & $\mathrm{N} / \mathrm{A}$ & $\begin{array}{l}\text { NO MV < } \quad \text { HS } \\
44 \% ;>H S 56 \% \\
\text { YES to MV } \\
30 \%<\text { HS } 70 \%> \\
\text { HS }\end{array}$ & COPD \\
\hline $\begin{array}{l}\text { Yeakle \& Allen } \\
(2007)\end{array}$ & 8 & $\begin{array}{l}\text { Exp: } \\
74 \\
\text { Ctrl: } \\
75\end{array}$ & USA & $\begin{array}{l}\text { Exp: } \\
50 \% \text { F, 50\% M } \\
\text { Control: } \\
75 \% \text { F, 25\% M }\end{array}$ & $\begin{array}{l}\text { Exp } \\
75 \% \text { Black } \\
\text { 25\% White Ctrl } \\
50 \%-B l a c k \\
50 \% \text {-White }\end{array}$ & $\begin{array}{l}\text { Exp } 13.75 \mathrm{Ctrl} \\
11.50\end{array}$ & $\mathrm{~N} / \mathrm{A}$ \\
\hline $\begin{array}{l}\text { Allen et al. } \\
(2008)\end{array}$ & 78 & $\begin{array}{l}\text { Exp } 75 \\
\text { Ctrl } 74\end{array}$ & USA & $\begin{array}{l}\text { Exp } \\
27 \% \mathrm{M} ; 73 \% \mathrm{~F} \\
\text { Ctrl } \\
31 \% \mathrm{M} ; 68 \% \mathrm{~F}\end{array}$ & $\begin{array}{l}\text { Exp } \\
54 \% \text { White } \\
45 \% \text { Black } \\
\text { Ctrl } \\
\text { 51\% White 48\% } \\
\text { Black }\end{array}$ & $\begin{array}{l}\text { Education years } \\
14 \text { Exp } \\
13.6 \mathrm{Ctrl}\end{array}$ & N/A \\
\hline $\begin{array}{l}\text { Chiou, \& Chung } \\
\text { (2011) }\end{array}$ & 60 & $\begin{array}{l}\text { Exp57 } \\
\text { Ctrl } 59\end{array}$ & Taiwan & $\begin{array}{l}\text { Exp: } 53 \% \mathrm{M} ; 46 \% \mathrm{~F} \\
\text { Ctrl: } 50 \% \mathrm{M} ; 50 \% \mathrm{~F}\end{array}$ & $\mathrm{~N} / \mathrm{A}$ & $\begin{array}{l}\text { Exp } \\
7.2 \text { years } \\
\text { Ctrl } \\
6.5 \text { years }\end{array}$ & ESRD \\
\hline
\end{tabular}




\begin{tabular}{|c|c|c|c|c|c|c|c|}
\hline $\begin{array}{l}\text { El-Jawahri, et al. } \\
(2010)\end{array}$ & 50 & $\begin{array}{l}\text { Exp } 56 \\
\text { Ctrl } 51\end{array}$ & USA & $\begin{array}{l}\text { Exp: } 39 \% \mathrm{~F} \\
\text { Ctrl: } 48 \% \mathrm{~F}\end{array}$ & $\begin{array}{l}\text { Exp } \\
\text { 95.7\% White } \\
\text { Ctrl } \\
88.9 \% \text { White }\end{array}$ & $\begin{array}{l}\text { Exp } \\
26 \% \leq \text { HS } 74 \% \geq \\
\text { College } \\
\text { Ctrl } \\
18.5 \% \leq \text { HS } \\
81 \% \geq \text { College }\end{array}$ & Cancer \\
\hline $\begin{array}{l}\text { Leighl et al. } \\
\text { (2011) }\end{array}$ & 207 & $\begin{array}{l}\text { Exp } 61 \\
\text { Ctrl } 62\end{array}$ & $\begin{array}{l}\text { Australia \& } \\
\text { Canada }\end{array}$ & $\begin{array}{l}\text { Exp: } 54 \% \text { M; } 46 \% \mathrm{~F} \\
\text { Ctrl: } 62 \% \text { M; 38\% F }\end{array}$ & N/A & $\begin{array}{l}\text { Exp } \\
53 \% \leq \text { HS } 47 \% \geq \\
\text { College } \\
\text { Ctrl } \\
52 \% \leq \text { HS } \\
48 \% \geq \text { College }\end{array}$ & Cancer \\
\hline $\begin{array}{l}\text { Tung et al. } \\
\text { (2011) }\end{array}$ & 574 & N/A & USA & $\begin{array}{l}\text { Exp: } 56 \% \mathrm{~F} \\
\text { Ctrl: } 49 \% \mathrm{~F}\end{array}$ & $\begin{array}{l}\text { Exp } \\
93.4 \% \text { White } \\
\text { Ctrl } \\
\text { 95.9\% White }\end{array}$ & $\begin{array}{l}\text { Exp } \\
43 \% \leq \text { HS 56\% } \geq \\
\text { College } \\
\text { Ctrl } \\
49 \% \leq \text { HS } \\
48 \% \geq \text { College }\end{array}$ & N/A \\
\hline
\end{tabular}

Notes: MV=Mechanical Ventilation, Exp=Experimental group, Ctrl=Control group, $\mathrm{HS}=\mathrm{High}$ School, N/A=Not applicable or not reported in the manuscript 


\section{Quality of the Studies}

The authors utilized the Johns Hopkins Nursing Evidence Based Practice Research Evidence Appraisal Tool to evaluate the rigor of the research (Dearholt \& Dang, 2012). According to the tool, the following criteria are characteristics of a high quality publication: "consistent results, sufficient sample size, adequate control, and definitive conclusions; consistent recommendations based on extensive literature review that includes thoughtful reference to scientific evidence". A good quality study has: "reasonably consistent results, sufficient sample size, some control, and fairly definitive conclusions; reasonably consistent recommendations based on fairly comprehensive literature review that includes some reference to scientific evidence" and low quality studies are characterized by "little evidence with inconsistent results, insufficient sample size, conclusions cannot be drawn" (Newhouse, Dearholt, Poe, Pugh \& White, 2007, p. 198). Methodological quality indicated by risk for potential biases is also considered in rating study quality. See Table 3 for the studies, their overall quality ratings and their potential study biases. 
Table 2-3

Sources of Potential Study Bias and Quality Rating

\begin{tabular}{|c|c|c|c|c|c|c|c|c|c|}
\hline \multirow[b]{2}{*}{ Authors } & \multicolumn{7}{|c|}{ Sources of Bias } & \multirow[b]{2}{*}{ Allocation } & \multirow{2}{*}{$\begin{array}{l}\text { Quality } \\
\text { Rating }\end{array}$} \\
\hline & Selection & \begin{tabular}{|l|} 
Data \\
Collection \\
\end{tabular} & $\begin{array}{l}\text { Integrity of } \\
\text { intervention }\end{array}$ & $\begin{array}{l}\text { Statistical } \\
\text { Analysis }\end{array}$ & Attrition & Detection & Confounding & & \\
\hline Chelf et al. (2002) & $x$ & & & & & & & & Good \\
\hline Davison, (2010) & $x$ & $x$ & & $x$ & & & & & High \\
\hline $\begin{array}{l}\text { Sudore et al. } \\
(2010)\end{array}$ & $x$ & & $x$ & $x$ & & & & & Good \\
\hline Dales et al. (1999) & $x$ & $x$ & & $x$ & $x$ & & & & Low \\
\hline $\begin{array}{l}\text { Mitchell et al. } \\
(2001)\end{array}$ & $x$ & $x$ & & & & & & & Low \\
\hline $\begin{array}{l}\text { Reinke et al. } \\
\text { (2011) }\end{array}$ & $x$ & $x$ & & $x$ & & & & & Low \\
\hline $\begin{array}{l}\text { Volandes et al. } \\
\text { (2010) }\end{array}$ & $x$ & & & $x$ & & & & & High \\
\hline $\begin{array}{l}\text { Wilson et al. } \\
\text { (2005) }\end{array}$ & $x$ & $x$ & & $x$ & & $\mathrm{x}$ & & & Low \\
\hline $\begin{array}{l}\text { Yeakle \& Allen } \\
\text { (2007) }\end{array}$ & $x$ & $x$ & $\mathrm{x}$ & $x$ & & $x$ & $x$ & $x$ & Low \\
\hline
\end{tabular}




\begin{tabular}{|c|c|c|c|c|c|c|c|c|c|}
\hline Allen et al. (2008) & $\mathrm{X}$ & & $x$ & & & $x$ & & $x$ & High \\
\hline $\begin{array}{l}\text { Chiou, \& Chung } \\
\text { (2011) }\end{array}$ & $x$ & & & & $x$ & $x$ & & $x$ & High \\
\hline $\begin{array}{l}\text { El-Jawahri, et al. } \\
(2010)\end{array}$ & $\mathrm{X}$ & $x$ & & & & & $\mathrm{x}$ & & High \\
\hline Leighl et al. (2011) & $x$ & & & & & $x$ & & & Good \\
\hline Tung et al. (2011) & $\mathrm{X}$ & $x$ & & $x$ & $x$ & $x$ & $x$ & $x$ & High \\
\hline
\end{tabular}


Potential study biases. In addition to assessing the studies for overall quality, they were also reviewed for potential biases. Eight potential biases were identified at varying frequencies in this group of studies. All 14 studies exhibit an increased risk for selection bias due to relatively small sample sizes. Selection bias occurs when there are differing characteristics between participants and individuals in the general population (Cochrane Public Health Group, n.d.).

Allocation bias occurs when the control group and the experimental group are assembled in a way that does not allow everyone the same opportunity to receive the intervention; this is higher in studies that are not randomized controlled trials (RCTs), (Cochrane Public Health Group, n.d.). Six of these studies were two group designs but only two were RCTs. In two studies, the researchers stated they randomly allocated but did not explain the method of randomization (Allen et al., 2008; Yeakle \& Allen, 2007).

Confounding bias occurs when there are extraneous factors besides the intervention that could contribute to the outcomes. The best way to minimize this risk is to randomize participants to evenly distribute known and unknown confounding factors between the intervention and control group. (Cochrane Public Health Group, n.d.). Three of the studies were at risk for confounding bias (El-Jawahri et al., 2010; Tung et al., 2011; Yeakle \& Allen, 2007).

Integrity of the intervention has five components that must be addressed in order to evaluate the quality of the intervention. Those components are adherence, exposure, and quality of delivery, participant responsiveness, and program differentiation (Cochrane Public Health Group, n.d.). The interventions utilized in this 
review were 12 decision aids. Most of the researchers of interventional studies (64\%) disclosed some technique for increasing the rigor of the intervention to minimize this bias (Chiou, \& Chung, 2011; Dales et al., 1999; El-Jawahri et al., 2010; Leighl et al., 2011; Mitchell et al., 2001; Reinke et al., 2011; Tung et al., 2011; Volandes et al., 2010; Wilson et al., 2005).

Attrition bias results when participants drop out from the study which could result in differences between control and intervention groups (Cochrane Public Health Group, n.d.). Despite this body of literature focusing on EOL issues, risk for attrition bias was surprisingly low in these studies. There were only five studies that had multiple data collection points, and $60 \%$ of those did not report attrition (Leighl et al., 2011; Reinke et al., 2011; Wilson et al. 2005).

Detection bias is likely to occur when data collectors are aware of which participants received the intervention and which did not. Blinding is a sound method for minimizing this bias (Cochrane Public Health Group, n.d.). Many researchers did not state if they utilized blinding (Allen et al., 2008; Chiou \& Chung, 2011; Dales et al., 1999; Davison, 2010; Mitchell et al., 2001; Sudore et al., 2010; Volandes et al., 2010; Tung et al., 2011; Wilson et al., 2005; Yeakle \& Allen, 2007). Researchers of two studies disclosed they did not employ blinding (El-Jawahri et al., 2010; Leighl et al., 2011).

In order for the results of a study to be sound, the instruments used to measure outcomes must be reliable and valid (Cochrane Public Health Group, n.d.). Half of the researchers gave no psychometrics for their instruments (Chelf et al., 2002; Davison, 2010; Mitchell et al., 2001; Sudore et al., 2010; Tung et al., 2011; Wilson et al., 2005). 
Statistical analysis bias refers to the adequacy in sample size to produce enough power to reach statistical significance in the results (Cochrane Public Health Group, n.d.). The majority of the studies (79\%) did not report performing a priori analyses (Allen et al., 2008; Chelf et al., 2002; Dales et al., 1999; Davison, 2010; El-Jawahri et al., 2010; Leighl et al., 2011; Mitchell et al., 2001; Reinke et al., 2011; Sudore et al., 2010; Tung et al., 2011; Volandes et al., 2010).

\section{Variables \& Measures}

Two of the studies explored preferences for learning and three specifically asked about preference for type of DA (Chelf et al., 2002; Davison et al., 2010, Tung et al., 2011). Decisional conflict or uncertainty was measured in 10 of the 14 studies (Allen et al., 2008; Chiou \& Chung, 2011; Dales et al., 1999; Davison, 2010; El-Jawahri et al., 2010; Leighl et al., 2011; Mitchell et al., 2001; Volandes et al., 2010; Wilson et al., 2005; Yeakle \& Allen, 2007). The Decisional Conflict Scale, in its entirety or the uncertainty subscale, was utilized in eight of the 10 studies that measured decisional conflict or uncertainty (Allen et al., 2008; Dales et al., 1999; El-Jawahri et al., 2010; Leighl et al., 2011; Mitchell et al., 2001; Volandes et al., 2010; Wilson et al., 2005; Yeakle \& Allen, 2007). Dales et al. (1999) used the 16-item version of the Decisional Conflict Scale on a 5-point Likert scale. Volandes et al. (2010) used only the uncertainty subscale of the Decisional Conflict Scale. Yeakle and Allen (2007) and Allen et al. (2008) used the 10-item, three response version of the Decisional Conflict Scale. Chiou \& Chung (2011) utilized a Scale of Uncertainty. They also measured DM regret utilizing a Chinese version of a Decision Making Regret Scale. Others used unnamed questionnaires (Davison, 2010) or just one 
question (Sudore et al., 2010) to measure DC. See Table 1 for Study Outcomes and Measures.

Decisional conflict. Ten of the 14 studies explored DC. Decisional conflict refers to uncertainty about which action to take (O'Connor, 1993). Defining characteristics of DC are individuals verbalizing uncertainty, concern over negative outcomes, wavering between choices, delaying DM, being preoccupied with DM, and exhibiting signs of tension or stress (O'Connor \& Jacobsen, 2001). Uncertainty is the "hallmark of decisional conflict" (O’Connor \& Jacobsen, 2001, p. 8). Many researchers utilized interventions to decrease DC with mostly positive results. These interventions provided information on EOL. Research indicates that more information regarding life-sustaining treatments results in less DC for individuals (Allen et al., 2008). More information can be delivered via DAs to assist in decreasing DC.

\section{Personal characteristics associated with decisional conflict. Personal}

characteristics impact DC and are associated with learning preferences. Being a woman associated with higher DC while being older associated with lower DC (Allen et al. 2008). Greater DC was associated with less desire for life-sustaining treatment in individuals with Alzheimer's disease $(r=-.74, p=.04)$ and emphysema $(r=-.80, p=.02)$. Greater DC was also significantly associated with greater cognitive impairment $(r=-.83, p=.01)$ (Yeakle \& Allen, 2007). Leighl et al. (2011) found decisional conflict levels unrelated to use of the DA, patient age, anxiety levels, or sex. Sudore et al., (2010) also found associations among race and DC. Asian/Pacific Islanders and Latinos were more likely to experience DC than Black Americans and Caucasians. Additional characteristics 
associated with higher DC were lower income and fair-to-poor health status (Sudore et al., 2010). In a study of diverse older adults, Sudore et al., (2010) found several characters associated with decisional conflict. When adjusting for confounding variables other than race, limited versus adequate literacy was associated with uncertainty. When leaving literacy in, being Latino or Asian/Pacific Islander versus White associated with uncertainty. Leaving literacy and race in adjusted multivariate models, limited literacy (AOR 2.121; 95\% Cl: 1.03 - 4.33) or being Latino (AOR 2.50; 95\% Cl: 1.01 - 6.16) or Asian/Pacific Islander (AOR 4.25; 95\% Cl: 1.22 - 14.76) versus White was still independently associated with uncertainty. Fair-to-poor health was associated with uncertainty in all models tested (AOR 2.11; 95\% Cl 1.04 - 4.28). Being Black American was not associated with uncertainty.

Participants whose primary language was not English or those who spoke primarily Spanish reported more uncertainty, $p<.001$. Education levels resulted in borderline significance. Those individuals with less than a high school education associated with more uncertainty than those with higher education, $p=.05$. Being born outside the U.S. was associated with uncertainty $p<.001$, (Sudore et al., 2010).

Health literacy is another personal characteristic that impacts EOL DM. Researchers found an association between lower and marginal literacy and DC; individuals with lower and marginal literacy experienced higher DC (Sudore et al., 2010). In the intervention study conducted by Volandes et al., (2010) individuals viewed a video depicting an individual with advanced dementia. Individuals with lower health literacy experienced more uncertainty about EOL than individuals with normal health 
literacy. Video DA improved EOL DM by decreasing uncertainty regarding subjects' preferences, especially limited literacy (Volandes et al., 2010). See Table 4 for summary of concepts.

Use of decision aids. Most researchers found DAs can assist in EOL DM. O'Connor (2006) defines patient DAs as "evidence-based tools to prepare people to participate in making specific and deliberated choices among healthcare options in ways they prefer" (p. 3). Decision aids come in many forms: booklets audio-booklets, videointernet based, webinars, video plus booklet, videos, and computerized. However, findings are inconclusive about which type of DA participants prefer to learn from best.

Twelve studies included decision aid interventions ranging from basic written educational material to multimedia electronic tools. Of the 12 interventions, $75 \%$ had some technology component. The interventions employed included hypothetical scenarios (Sudore et al., 2010; Yeakle, \& Allen, 2007; Allen et al., 2008), audio-booklets (Dales et al., 1999; Leighl et al., 2011; Mitchell et al., 2001; Wilson et al., 2005), webconferencing with a still-frame picture of the discussion facilitator (Reinke et al., 2011), video (Volandes et al., 2010), video with verbal discussion (El-Jawahri et al., 2010), multimedia DVD and telephone follow-up, (Chiou \& Chung, 2011), and written information (Tung et al., 2011). The interventions were successful in decreasing decisional conflict in all but two studies (Leighl et al., 2011; Yeakle \& Allen, 2007). Leighl et al., (2011) found similar DC scores in both the control and experimental groups. Yeakle and Allen (2007) found an increase in DC in the experimental group participants. The DAs in these two studies were similar to DAs employed in studies that recognized a 
decrease in DC. One of the studies used the Life Support Preferences Questionnaire which was also used by Allen et al. (2008) who found decreased DC in participants who had utilized the DA. Leighl et al. (2011) used an audio book and found no difference in intervention participants versus usual care participants, but an audio book was helpful in decreasing DC in other studies (Dales et al., 1999; Mitchell et al., 2001; Wilson et al., 2005).

Researchers sought to decrease patients' DM uncertainty using DAs to increase knowledge but found DAs decrease DC in some studies (Allen et al., 2008; Mitchell et al., 2001; Volandes, 2010) while increasing in others (Yeakle \& Allen, 2007). Yeakle and Allen (2007) found the intervention group, who received more information, experienced more DC and exhibited less life-sustaining treatment knowledge (Yeakle \& Allen, 2007). In a study of patients with chronic obstructive pulmonary disease, the participants showed improvement in expectations of mechanical ventilator outcomes after the DA $(P<0.001)$, which was a video, and decrease in DC score $(P<0.001)$ (Wilson et al., 2005). After viewing a video, participants felt comfortable with DM. Uncertainty scores increased ( $0=$ completely uncertain to $15=$ total certainty) significantly in the video group which translates to less uncertainty (El-Jawahri et al., 2010). In another study exploring the efficacy of a DA, DC differed significantly between the two groups (t (76) $=2.00, P=.049, d=0.47)$. Participants had less $D C$ if they had received the additional information $8.49 \pm 8.82$ versus $12.98 \pm 10.75$ (Allen et al., 2008).

Decision aids had no impact on DC scores in a study of individuals with advanced cancer. Decisional conflict levels were unrelated to use of the DA (Leighl et al., 2011). A 
DA was effective in assisting DM for surrogate decision makers regarding tube feeding placement. Decisional conflict was lower after participants utilized a decision aid. Leighl et al. (2011) also found EOL tube feeding knowledge increased after viewing the DA $(84.0 \% \pm 13.5[\mathrm{SD}]$ versus $50.4 \% \pm 13.5[\mathrm{SD}], \mathrm{P}=.004)$. In terms of predisposition to options, the DA impacted the decisions of those who were unsure of their decision, but had no influence on those who were committed to their decisions. Those who were definitively for or against the tube feedings were unchanged by the DA (Mitchell et al., 2001). Decision aid interventions are useful in the EOL DM process. They show promise in helping individuals make decisions regarding their EOL wishes as well as increasing their satisfaction with the decisions and reducing their DC.

Preferences for type of decision aid. In this body of literature, the studies exploring preferences for mode of receiving healthcare information were limited. Only three of the studies included information on preferences for type of DA. Two of these studies were in the top three in terms of largest sample size (Chelf et al., 2002; Tung et al., 2011). In one study, participants with cancer favored talking with physicians (66\%), reading information in brochures or booklets $(33 \%)$, discussions with nurses $(34 \%)$, print media on information displays (20\%) and speaking with other cancer patients (14\%). A large portion (68\%) also admitted they would be willing to call a toll free number to receive healthcare information. Participants in this study were not interested in computer assisted learning (Chelf et al., 2002). Participants with chronic kidney disease reported they normally receive information from their specialist (79.5\%), family physician (65.8\%), family or friends (43.8\%), paper resources $(25.7 \%)$, internet $(16 \%)$ and 
television/media (12.8\%) (Davison et al., 2010). This report, however, was how they normally receive the information not how they wished to receive the information. Reinke et al. (2011) utilized a webinar in their study of using a webinar as a DA to teach patients with COPD about EOL communication. The participants liked the ease of use of a webinar, but all participants felt a video stream would make the webinar easier to follow. The webinar held a still shot of the discussion facilitator's face. Despite this limitation, following the webinar, all participants took some form of action regarding EOL decisions (Reinke et al., 2011). In a study of patients from a primary care physicians' office, more than $80 \%$ preferred written materials $(n=58), 37.5 \%$ preferred personal discussions with health care provider $(n=27)$, and $11.1 \%$ preferred video / TV $(n=8)$, and 5.6\% preferred the internet $(n=4)$ (Tung et al., 2011). Age, education, and gender are associated with learning preferences. Participants older than 60 preferred fewer learning methods, on the other hand, women and individuals with higher education were more likely to find a variety of learning methods acceptable (Chelf et al., 2002).

\section{Discussion}

Although there is a large body of research exploring DAs, studying DAs with EOL DM is still underdeveloped. Many of the EOL DM studies were methodological studies evaluating DAs that have been created. Sample sizes were small but results were promising in the ability of DAs to lower DC and assist with DM.

Ten of the fourteen studies explored DC. Research indicated that information regarding life-sustaining treatments resulted in less DC for individuals (Allen et al., 2008). Patient DAs show promise in decreasing DC (Mitchell et al., 2001). However, DAs 
are not effective all of the time. Some researchers did not find favorable results with their DAs. The DA employed in a study of individuals with advanced colorectal cancer had no impact on decisional conflict (Leighl et al., 2011).

Several personal characteristics are associated with DC such as race, age, and health literacy. Individuals with low, marginal, and limited literacy experienced more uncertainty in DM (Volandes et al., 2010). Uncertainty, the defining attribute of DC, was associated with Hispanic, Latino, or Asian/Pacific Islander race/ethnicity, lower income, fair-to-poor health status, and less than high school education (Sudore et al., 2010). Participants who spoke English as a second language or spoke Spanish as their primary language experienced more decisional conflict (Sudore et al., 2010). Decisional conflict levels were unrelated to use of the DA, patient age, anxiety levels, or gender (Leighl et al., 2011). Personal characteristics impact DC and are associated with learning preferences. Age, education, and gender are associated with learning preferences. Participants older than 60 preferred fewer learning methods, on the other hand, women and individuals with higher education were more likely to find a variety of learning methods acceptable (Chelf et al., 2002). Alzheimer's, emphysema, and cognitive impairment are also associated with increased DC.

Nine of the 14 studies in this review were either high or good quality. Five studies were weak in their design. Despite the majority of participants favoring written material or discussions with their physician, $75 \%$ of the DAs have some technological basis. This raises the question of whether healthcare personnel take into consideration the desires of participants or push technological interventions that the healthcare 
consumers may not desire. Decision aids show promise in reducing decisional conflict, but the evidence is not conclusive. More research is needed in diverse, elderly populations. End-of-life DM can be enhanced through DAs which are effective in healthcare DM. Decision aids come in many forms but the existing literature does not identify the best mode of DA. Decision aids are effective in decreasing DC in some studies while proving ineffective (Leighl et al., 2011) or even detrimental in others by increasing DC (Yeakle \& Allen, 2007). Decision aids show promise in helping individuals make decisions regarding their EOL wishes as well as increasing their satisfaction with the decisions and reducing their DC. Preferences for mode of receiving healthcare information are quite varied. Participants listed a multitude of modes they preferred such as talking with physicians, reading information in brochures or booklets, discussions with nurses, print media on information displays (20\%) and speaking with other cancer patients (14\%). In one study of 625 participants, there was no interest in computer-assisted learning (Chelf et al., 2002), yet the majority of DAs are technologybased.

\section{Implications for Practice}

Practitioners need to develop educational materials utilizing modes that patients prefer to assist them in EOL DM. Most likely, the answer will not be a one size fits all solution. Identifying the most desired DA modes will allow the healthcare community to develop teaching tools in ways that will benefit the consumer and multiple tools will most likely be the answer. Until the healthcare community identifies the preferences, developing DAs may be futile. Educators must continually strive to assess the learning 
preferences of their audience and provide effective therapeutic teaching materials. This review illustrates that more assessments of learning preferences are needed.

\section{Implications for Research}

The mean age of participants in this review was 60 which is fairly young for those considering EOL decisions. Elders who are 75 and older represent a cohort of individuals who grew up in another era and may view death differently, such as viewing death as imminent or as an opportunity to join loved ones who have already died (Gott, Small, Barnes, Payne, \& Seamark, 2008). Studies are needed in those participants older than 60 to identify preferred learning methods to develop DAs tailored to the needs of those who could benefit in EOL DM assistance. A gap in the literature exists exploring the preferred type of DA in elder individuals and exploring characteristics related to incidences of DC in individuals older than 75 years old. The findings in this systematic review are mostly positive but could still be considered inconclusive regarding whether technology-based DAs are effective in decreasing DC. The literature indicates that age, gender and education have an impact on decisional conflict and learning preferences. 


\section{References}

Allen, R.S., Allen, J.Y., Hilgeman, M.M. \& DeCoster, J. (2008). End-of-life decision-making, decisional conflict and enhanced information: Race effects. Journal of American Geriatric Society, 56, 1904-1909.

Bunn, H., Lange, I., Urrutia, M., Campos, M.S., Campos, S., Jaimovich, S., Campos, C., Jacobsen, M.J., \& Gaboury, I. (2006). Health preferences and decision-making needs of disadvantaged women. Journal of Advanced Nursing, 56, 247-260.

Chelf, J.H., Deshler, A., Thiemann, K., Dose, A.M., Quella, S.K. \& Hillman, S. (2002). Learning and support preferences of adult patients with cancer at a comprehensive cancer center. Oncology Nursing Forum, 29, 863-867.

Cochrane Public Health Group (n.d.) Unit eight: Principles of critical appraisal. Retrieved from http://ph.cochrane.org/sites/ph.cochrane.org/files/uploads/Unit_Eight.pdf

Dales, R.E., O'Connor, A., Hebert, P., Sullivan, K., McKim, \& Llewellyn-Thomas, H. (1999). Intubation and mechanical ventilation for COPD*: Development of an instrument to elicit patient preference. CHEST, 116, 792-800.

Dearholt, S.L. \& Dang, D. (2012). Johns Hopkins nursing evidence-based practice model and guidelines, 2nd Ed. Indianapolis, IN: Sigma Theta Tau International.

Edwards, A. \& Elwyn, G. (2001). Evidence-based patient choice. Oxford: Oxford University Press.

El-Jawahri, Al., Podgurski, L.M., Eichler, A.F., Plotkin, S.R., Temel, J.S., Mitchell, S.L., Chang, Y., Barry, M.J. \& Volandes, A.E. (2009). Use of video to facilitate end-oflife-discussions with patients with cancer: A randomized controlled trial. Journal of Clinical Oncology, 28, 305-310.

Gott, M., Small, N., Barnes, S., Payne, S., \& Seamark, D. (2008). Older people's views of a good death in heart failure: Implications for palliative care provision. Social Science \& Medicine, 67, 1113-1121.

Heyland, D.K., Frank, C., Groll, D., Pichora, D., Dodek, P., Rocker, G., \& Gafni, A. (2006). Understanding cardiopulmonary resuscitation decision making. CHEST, 130, 419428. doi 10.1378/chest. 130.2.419

Leatheran, S. \& Warrick, L. (2008). Effectiveness of decision aids. A review of the evidence. Medical Care Research and Review, 65, 79-116.

Leighl, N.B., Shepherd, H.L., Butow, P.N., Clarke, S.J., McJannett, M., Beale, P.J. ... \& Tattersall, M.H.N. (2011). Supporting treatment decision making in advanced cancer: A randomized trial of a decision aid for patients with advanced colorectal cancer considering chemotherapy. Journal of Clinical Oncology, 29, 1-9.

Levi, B.H. \& Green, M.J. (2010). Too soon to give up: Re-examining the value of advance directives. The American Journal of Bioethics, 10, 3-22.

Mitchell, S.L., Tetroe, J., \& O'Connor, A.M. (2001). A decision aid for long-term tube feeding in cognitively impaired older persons. Journal of American Geriatric Society, 49, 313-31. 
Montgomery, A.A., Fahey, T., \& Peters, T.J. (2003). A factorial randomized controlled trial of decision analysis and an information video plus leaflet for newly diagnosed hypertensive patients. British Journal of General Practice, 53, 446-453.

Newhouse, R.P., Dearholt, S.L., Poe, S.S., Pugh, L.C., \& White, K.M. (2007). Johns Hopkins nursing evidence-based practice model and guidelines. Indianapolis, IN: Honor Society of Nursing, Sigma Theta Tau International.

O’Connor, A.M. (1999). The Decisional Conflict Scale. Retrieved from www.ohri.ca/decisionaid.

Porensky, E.K. \& Carpenter, B.D. (2008). Knowledge and perceptions in advance care planning. Journal of Aging and Health, 20, 89-106.

Reinke, L.F., Griffith, R.G., Wolpin, S., Donesky-Cuenco, D., Carrieri-kohlman, V., \& Nguyen, H.Q. (2011). Feasibility of a webinar for coaching patients with chronic obstructive pulmonary disease on end-of-life communication. American Journal of Hospice Palliative Care, 28, 147-152.

Sudore, R.L., Schillinger, D., Knight, S.J. \& Fried, T.R. (2010). Uncertainty about advance care planning treatment preferences among diverse older adults. Journal of Health Communication, 15, 159-171.

Tung, E.E., Vickers, K.S., Lackore, K., Cabanela, R., Hathaway, J., \& Chaudhry, R. (2011). Clinical decision support technology to increase advance care planning in the primary care setting. American Journal of Hospice \& Palliative Medicine, 28, 230235.

Volandes, A.E., Barry, M.J., Chang, Y., \& Paasche-Orlow, M.K. (2010). Improving decision making at the end of life with video images. Medical Decision Making, 30, 29-34.

Wilson, K.G., Blackron, S.D., Vandemheen, K.L., Hebert, P.C., McKim, D.A., Fiset, V., Graham, I.D., Sevigny, E., \& O'Connor, A.M. (2005). Evaluation of a decision aid for making choices about intubation and mechanical ventilation in chronic obstructive pulmonary disease. Patient Education and Counseling, 57, 88-95.

Yeakle, J. \& Allen, R. (2007). Piloting EDMAC: The end-of-life decision making and memory complaint project. University of Alabama Mcnair Journal. 195-215. Retrieved from http://www.graduate.ua.edu/mcnair/journals/2007/Yeakle.pdf. 
CHAPTER III

PERSONAL CHARACTERISTICS AND LEARNING PREFERENCES IN END-OF-LIFE DECISION MAKING OF CHRONICALLY ILL COMMUNITY DWELLING ELDERS:

\title{
AN EXPLORATORY STUDY
}

\begin{abstract}
Clear decision-making (DM) contributes to a good death (American Nursing Association, 2001) but lack of knowledge is a barrier to decision making (Heyland et al., 2006). Patient decision aids can increase knowledge, but elders' preferred learning method is unknown. The purpose of this study was to explore patient characteristics that contribute to decisional conflict and preferences for type of decision aid to assist learning about EOL care. The Ottawa Decision Support Framework (O'Connor, 1995) served as the conceptual framework. This exploratory, descriptive study used a convenience sample of 115 chronically ill elders aged $>75$ years who lived independently in communities in Central Illinois. Volunteer participants completed a survey consisting of a demographics assessment, the Newest Vital Sign, the Decisional Conflict Scale, and the Symptom Distress Scale. Findings suggest that higher educated individuals have less decisional conflict, and women prefer discussions with healthcare providers compared with men.
\end{abstract}


Every dying patient deserves a good death (Steinhauser et al., 2000) and clear decision making contributes to this outcome (American Nursing Association, 2001). Knowledge of life-sustaining treatments is necessary for informed decision making about end-of-life (EOL) care, but findings suggest patients and families lack this knowledge (Beckstrand, Smith, Heaston, Bond, \& Jordan, 2006; Heyland et al., 2006; Mathieu et al., 2010; Porensky \& Carpenter, 2008; Song \& Sereika, 2006). Decisions about EOL care are among the most difficult decisions people face, especially when they have a poor understanding of life-sustaining treatments. Decision making requires information about available choices and involves a conscious process to choose one of those options (O'Connor, 2006). Making EOL decisions without sufficient information frequently leads to feelings of decisional conflict, defined by O'Connor et al. (1998) as uncertainty about course of action to take arising from factors inherent in the decision (uncertainty of outcomes, or the need to make value tradeoffs between benefits and risks) and modifiable factors (inadequate knowledge, unrealistic expectations, unclear values and norms, unwanted social pressure, inadequate social support, lack of other resources) (p. 270).

(Allen et al., 2008; Davison, 2010; Mitchell, Tetroe \& O’Connor, 2001; Volandes, Barry, Chang \& Paasche-Orlow, 2010).

Educating patients, an integral part of nursing, is most effective when the educational method aligns with learning preferences. However, learning about options at EOL is stressful (Thelan, 2005). Health care professionals need effective ways to 
educate individuals to decrease uncertainty and promote decision making (Porensky \& Carpenter, 2008). In addition, poor communication often exists between patients and physicians regarding EOL (Janssen, Spruit, Schols \& Emiel, 2010); discussions can appear to be one sided rushed speeches by physicians that do not effectively educate (Edwards \& Elwyn, 2001) and result in overwhelmed patients who do not process or retain information (Marbach \& Griffie, 2011).

Although chronic diseases (especially heart and respiratory disease) are leading causes of death, much EOL research focuses on self-limiting diseases such as cancer (United Census Bureau, 2011). Patients with chronic illness face different challenges than individuals with terminal illness in EOL decision making (Vidal \& Pandiella, 2010) due to the vague nature of knowing when EOL will occur (SUPPORT, 1995; Vidal \& Pandiella, 2010).

Decision aids show promise in improving decision making. O'Connor (2006) defines patient decision aids (DAs) as "evidence-based tools to prepare people to participate in making specific and deliberated choices among healthcare options in ways they prefer" (p. 3). Researchers have studied a variety of DAs (El-Jawahri, et al., 2009; Mitchell et al., 2001), but much remains unknown about the preferred type of DA to assist chronically ill elders making EOL decisions. A problem exists when knowledge is lacking, patients experience decisional conflict, and decision making is postponed to the EOL, which makes patients more vulnerable to life-sustaining treatments they may not desire. 


\section{Purpose}

The purpose of this study is to explore variables influencing EOL decision making in older, chronically ill, community dwelling elders. The study's research questions are, in chronically ill elders aged 75 or older living in the community:

a) What patient characteristics contribute to decisional conflict about EOL decisions?

b) What patient characteristics contribute to preferences for type of decision aid to assist learning about EOL care?

c) What is the feasibility of using an online survey methodology?

\section{Theoretical Framework}

The Ottawa Decision Support Framework (ODSF) provides a theoretical basis for this research. Figure 1 shows the ODSF as developed by O'Connor (2006). The ODSF framework has three domains: determinants of decisions, decision support, and evaluation of the decision (O'Connor et al., 1998). The determinants of decisions are "essential inputs into the decision" (O'Connor, 1998, p. 268). Decision support is a mediating factor between determinants of decisions and decision quality and outcomes. Appropriate decision support "addresses modifiable determinants of decisions that are suboptimal" (O'Connor et al., 1998, p. 269) and leads to higher quality decision making and, hopefully, better outcomes. The ODSF's focus is to support patients in decision making, and prepare individuals to make informed decisions (Murray, Miller, Fiset, O’Connor \& Jacobsen, 2004). 
Figure 1

Ottawa Decision Support Framework

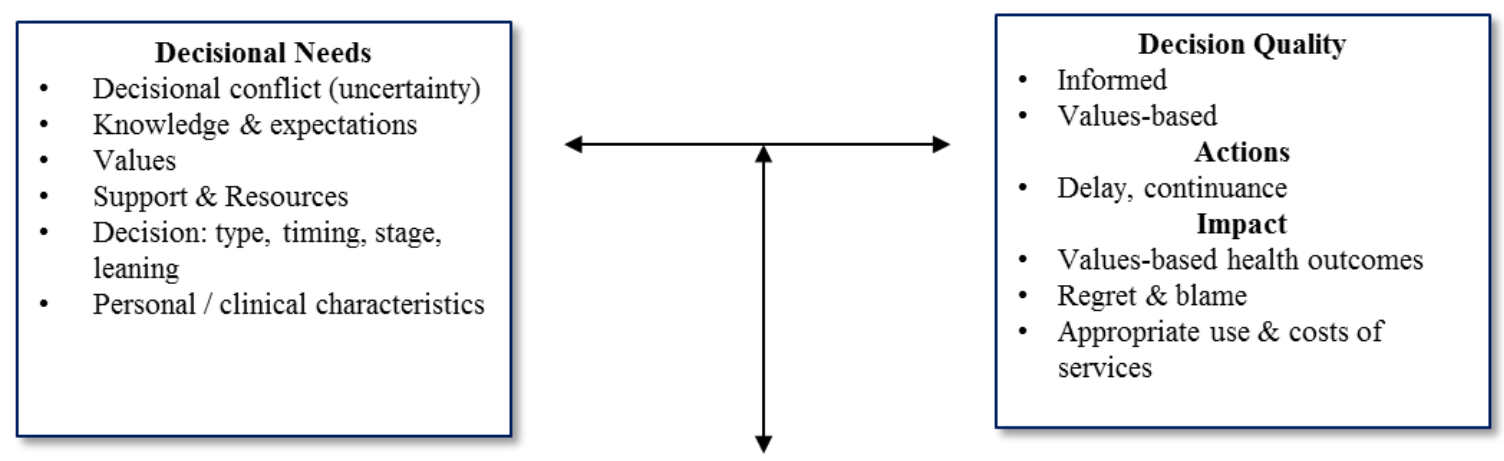

Decision Support

- Clarify decision \& needs

- Provide facts, probabilities

- Clarify values

- Guide in deliberation \& communication

- Monitor/ facilitate progress

Counseling Decision Tools Coaching

(O'Connor, 2006)

This study focuses on two domains of the ODSF: determinants of decisions (socio demographic variables such as gender, relationship status, education, and income, clinical characteristics such as type of chronic illness and disease burden, and perception of the decision such as decisional conflict) and decision support (preference for decision aid). Based on the literature, we adapted the framework to add health literacy as a personal characteristic. Eliciting information regarding variables surrounding EOL decision making, decisional conflict in EOL decision making, and necessary resources needed to make decisions can add to the EOL decision making science. The knowledge obtained could lead to the development of resources to assist individuals in EOL decision making. 


\section{Literature Review}

Articles included in the literature review were limited to primary research studies of adults published in English from 1998 to 2013 exploring the concepts of decisional conflict, variables associated with DC, or variables influencing preferences for type of DAs in EOL. Articles were retrieved from database searches of Cumulative Index of Nursing and Allied Health Literature (CINAHL), PubMed, Google Scholar, PsychInfo, using key terms: decisional conflict, decision making, end of life, knowledge, lifesustaining treatments, patient education, preference for learning, and technology-based decision aids. Reference lists of pertinent articles were explored as well as searching for notable authors' additional manuscripts. Reviewing titles and abstracts of 2800 "hits" and eliminating articles that were duplicates or not pertinent resulted in a final sample of 123 studies.

\section{Personal Characteristics Associated with Decisional Conflict}

Personal characteristics impact DC. Being a woman is associated with more DC (Allen et al., 2008), as is having emphysema, cognitive impairment, lower income, or fair-to-poor health status (Sudore et al., 2010). Individuals with less than a $12^{\text {th }}$ grade education experienced more DC than those with higher education (Sudore et al., 2010). Individuals with lower and marginal literacy experienced higher DC (Sudore et al., 2010; Volandes et al., 2010). Less DC is associated with being older and possessing more information regarding life-sustaining treatments (Allen et al., 2008). 


\section{Decision Aids}

Several researchers explored how DAs can assist in EOL DM. Researchers sought to decrease patients' DC using DAs but found variable results; DAs decrease DC in some studies (Allen et al., 2008; El-Jawahri et al., 2010; Mitchell et al., 2001; Volandes et al., 2010; Wilson et al., 2005) while increasing DC in others (Yeakle \& Allen, 2007). Wilson et al. (2005) found that an audio booklet DA helped over $90 \%$ of participants make a decision regarding mechanical ventilation, with improvement in expectations of mechanical ventilation outcomes and decrease in DC. Mitchell et al. (2001) also found an audio booklet increased knowledge and lowered DC in surrogate decision makers of cognitively impaired individuals. Allen et al. (2008) found a booklet DA using illness scenarios lowered DC in participants. El-Jawahri et al. (2010) studied videotapes as a DA and found that $25.9 \%$ of their participants preferred life-prolonging care before viewing the video, but all individuals desired only comfort care after viewing it. Volandes et al. (2010) used a video DA illustrating advanced stages of dementia and found less DC. However, Yeakle and Allen (2007) found that the booklet DA presenting hypothetical illness scenarios increased DC in their participants. Decision aids had no impact on DC in a study of individuals with advanced cancer. Decisional conflict levels were unchanged by the use of the DA (Leighl et al., 2011).

\section{Preferences for Type of Decision Aid}

Few studies explored preferences for type of DA in EOL decision-making. Chelf et al. (2002) asked participants with cancer to indicate their preferred DAs, which included: talking with physicians (66\%), or nurses (34\%); reading information in brochures or 
booklets (33\%); print media on information displays (20\%); and speaking with other cancer patients (14\%), but not computer assisted learning (4\%). In a study of patients from a primary care physicians' office, preferences included written materials $(n=58$; 80.6\%) personal discussions with health care provider ( $n=27 ; 37.5 \%)$, video / TV $(n=8$; 11.1\%), and internet ( $n=4 ; 5.6 \%)$ (Tung et al., 2011). Reinke et al. (2011) utilized a webinar, with a still shot of the discussion facilitator's face, as a DA and found participants liked its ease of use. Age, education, and gender are associated with preference for DAs. Participants, older than 60 , preferred fewer learning methods, while women and individuals with higher education preferred a variety of learning methods (Chelf et al., 2002).

The literature indicates that personal characteristics are associated with DC (gender, age, education, income, health literacy, knowledge, Alzheimer's, emphysema, and cognitive impairment). Personal characteristics associated with preferences for type of DA, include age, education, and gender. More people preferred personal discussions with healthcare providers and written materials as DAs; though a variety of electronic DAs seem effective as well. Decision aids show promise in helping individuals make decisions regarding their EOL wishes as well as increasing their satisfaction with the decisions and reducing their DC. However, the evidence is not conclusive. Preferences for mode of DA are quite varied. More research is needed in diverse, elderly populations. 


\section{Methods}

This descriptive, exploratory, cross-sectional used a convenience sample of 115 participants was recruited from November 2012 to August 2013. Inclusion criteria were adults aged 75 years old or older, with at least one diagnosed chronic illness, living in the community (independently or in assisted-living), and able to read, write, and speak English. A power analysis for logistic regression was conducted using G*Power 3.1.3. The analysis revealed that the sample size of 129 was needed to obtain a power of 0.80 with a baseline probability of 0.20 , an odds ratio of 1.9 , a correlation of 0 and an alpha of 0.05 .

\section{Procedure}

Following IRB approval, participants for paper-based surveys were recruited through flyers and direct solicitation from assisted living facilities, senior group centers, local churches, clinics, gymnasiums, and post offices in several locations in Central Illinois. The principal investigator described the study, obtained informed consent, and administered the surveys. As an incentive, the principal investigator provided a brief educational summary of advance directives.

Online survey participants were solicited through fliers that contained the survey website address, social media (Facebook) and direct e-mail. Electronic mail addresses were obtained through personal communication with individuals or sent through third parties. When interested participants accessed the study website, the introductory webpage explained the study's purpose, procedure, risks and benefits, and primary researcher's contact information. The introductory statement indicated that if 
participants clicked the "Next" button, they were providing consent to participate in the study.

\section{Measures}

Participants completed an anonymous survey composed of several scales with associated psychometrics. An adaptation of the Population Needs Assessment had 24 questions which captured demographic information, experience with EOL discussions and preferences for type of decision aid. The Newest Vital Sign scale is a 6-item instrument which measured health literacy. The Symptom Distress Scale (SDS) is a 13item scale used to measure disease burden, and the Decisional Conflict Scale (DCS) is a 16-item instrument which assessed level of decisional conflict. Table 1 describes these scales and their psychometric properties.

Table 3-1

Instruments, Descriptions, and Psychometrics

\begin{tabular}{|l|l|l|}
\hline Instrument & Description and Psychometrics & Concept measured \\
\hline $\begin{array}{l}\text { Population Needs } \\
\text { and O'Connor (1999 } \\
\text { (updated 2006)) }\end{array}$ & $\begin{array}{l}\text { 24 check-box or fill-in-the-blank } \\
\text { questions re: demographics (14), } \\
\text { past history with EOL DM (9), } \\
\text { preference of type of DA (1) plus } \\
\text { open-ended question re: } \\
\text { assistance in making decisions (1) }\end{array}$ & $\begin{array}{l}\text { Determinants of } \\
\text { Decision: } \\
\text { Socio-demographic } \\
\text { characteristics; } \\
\text { clinical } \\
\text { characteristics }\end{array}$ \\
& $\begin{array}{l}\text { Nocision Support: } \\
\text { preference for DA }\end{array}$ \\
\hline
\end{tabular}




\begin{tabular}{|c|c|c|}
\hline Newest Vital Sign & $\begin{array}{l}\text { 6-item Food label with } 6 \\
\text { questions. Scores range from } 0 \text { to } \\
6 \\
0-1=\text { limited literacy } \\
2-3=\text { possibility of limited literacy } \\
4-6=\text { adequate literacy } \\
\text { Psychometrics: } \\
\text { Internal consistency (Cronbach's } \\
\text { alpha = 0.76) } \\
\text { Criterion validity (r=0.59, P <.001) } \\
\text { Correlates with the Test of Health } \\
\text { Literacy in Adults (Weiss et al., } \\
\text { 2005) }\end{array}$ & $\begin{array}{l}\text { Health related } \\
\text { literacy }\end{array}$ \\
\hline $\begin{array}{l}\text { Symptom Distress } \\
\text { Scale }\end{array}$ & $\begin{array}{l}\text { 13-item self-report questionnaire } \\
\text { Scores range from } 13 \text { to } 65 \text { with } \\
\text { higher scores correlating with } \\
\text { higher symptom distress. } \\
\text { Psychometrics: Cronbach's alpha } \\
\text { coefficients reported as high as } \\
0.92 \text { (Ragsdale \& Morrow, 1990). } \\
\text { Content validity was established } \\
\text { (McCorkle, Cooley \& Shea, 2000). }\end{array}$ & $\begin{array}{l}\text { Burden of chronic } \\
\text { illness }\end{array}$ \\
\hline $\begin{array}{l}\text { Decisional Conflict } \\
\text { Scale (DCS) }\end{array}$ & $\begin{array}{l}16 \text { item scale with five subscales: } \\
\text { uncertainty, knowledge, values } \\
\text { clarity, support, and effective- } \\
\text { decision making. Scores range } \\
\text { from } 0 \text { to 100. A higher score } \\
\text { indicates more decisional conflict } \\
\text { (O'Connor, 1999). } \\
\text { Psychometrics: } \\
\text { Test-re-test reliability } 0.81 \\
\text { Internal consistency Cronbach's } \\
\text { alpha ranging from } 0.78 \text { to } 0.92\end{array}$ & Decisional Conflict \\
\hline
\end{tabular}




\begin{tabular}{|l|l|l|}
\hline & (O'Connor, 1995). & \\
\hline $\begin{array}{l}\text { Reported number of } \\
\text { participants who } \\
\text { complete the survey } \\
\text { online. }\end{array}$ & $\begin{array}{l}\text { Feasibility of using } \\
\text { an online survey } \\
\text { methodology in a } \\
\text { sample of elders } \\
\text { aged 75 years and } \\
\text { older }\end{array}$ \\
\hline
\end{tabular}

\section{Statistical Analyses}

After data cleaning, all data were analyzed with SPSS 20.0 (IBM Corp, Armonk, NY, 2012). Frequencies and descriptive statistics were reported, including frequencies and percentages for categorical variables and means and standard deviations for continuous variables. Multiple linear regression was then utilized to document significant contribution of patient characteristic variables to decisional conflict with EOL decision making. Independent variables included gender, relationship status, education, income, health literacy, type of chronic illness, and disease burden. Univariate and multivariate logistic regression were conducted to identify variables predictive of preference for types of decisional aid. Independent variables included gender, relationship status, education, income, health literacy, type of chronic illness, and disease burden. Due to small sample size, we entered only significant variables found in univariate analyses into the multivariate logistic regression stepwise model to determine those that were independently related to the preference for types of decisional aid. Variables found in univariate regressions were included in multivariate if $p \leq .10$. All other statistical significance is then reported at $p \leq .05$. 


\section{Results}

\section{Sample Characteristics}

There were 115 participants with usable data; 100 completed paper surveys and 15 completed online surveys. Of 265 paper surveys distributed, 115 were returned (43.4\% response rate). Subjects had a mean age of 81.6 (SD=4.97, range $75-92)$. They were also primarily women (68.7\%), Caucasian (97.4\%), widowed or single $(55.7 \%)$, had a $12^{\text {th }}$ grade or under education $(53.6 \%)$ and rated their physical $(76.6 \%)$, emotional (75.7\%), cognitive (69.5\%) and social health (74.0\%) as good or excellent (See Table 2). Mean score on the Decisional Conflict Scale was 22.69 (SD = 16.40) which indicates this group did not experience high levels of DC. The Decisional Conflict Scale ranges from 0100 with highest being the most DC. Mean score on the Symptom Distress Scale was $21.99(S D=5.92)$ which indicates the participants are nearing moderate distress. Scores range from 13 to 65 and a score of 25 on the Symptom Distress Scale suggests moderate distress (McCorkle, Cooley, \& Shea, 2000). Health Literacy scores range from zero to six and were categorized into three categories. Scores of zero to one indicate limited literacy, two to three indicate possible limited literacy, and scores of four to six indicate adequate literacy. In our sample we had 34 individuals with limited literacy (29.5\%), 14 with possible limited literacy (12.2\%), and 67 individuals with adequate literacy (58.3\%).

Regarding EOL decisions, most participants rated their knowledge as "about right" or higher for EOL options ( $n=88 ; 76.5 \%$ ) and EOL treatment ( $n=89 ; 77.5 \%)$. Most had EOL discussions in the past $(n=101 ; 88.0 \%$ ) for themselves $(n=61 ; 60.0 \%$ ) or spouse ( $n=15 ; 14.8 \%$ ) and $68(59.1 \%)$ made EOL decisions in the past. EOL discussions had 
been with physicians ( $n=36 ; 31.3 \%)$, nurses $(n=10 ; 8.7 \%)$ and spouses $(n=19 ; 16.5 \%)$, and 59 (51.3\%) did not involve use of a decision aid. Participants preferred personal discussion with a healthcare provider as a decision aid to assist with EOL discussions ( $\mathrm{n}=$ 49; $42.6 \%)$, followed by booklet/pamphlet ( $n=19 ; 16.5 \%)$, booklets/pamphlets plus audio ( $n=14 ; 13.6 \%$ ), video/DVDs ( $n=7 ; 5.9 \%)$, and the internet $(n=7 ; 3.9 \%)$. Most participants wanted comfort care only at EOL ( $n=59 ; 51.3 \%$ ) followed by agreeing to an intravenous line for medications but no life-sustaining treatments ( $n=29 ; 25.2 \%)$, everything done (all treatment available) ( $n=13 ; 11.3 \%)$, and $13(11.3 \%)$ of them were unsure of their wishes.

Table 3-2

Sample Characteristics $(N=115)$

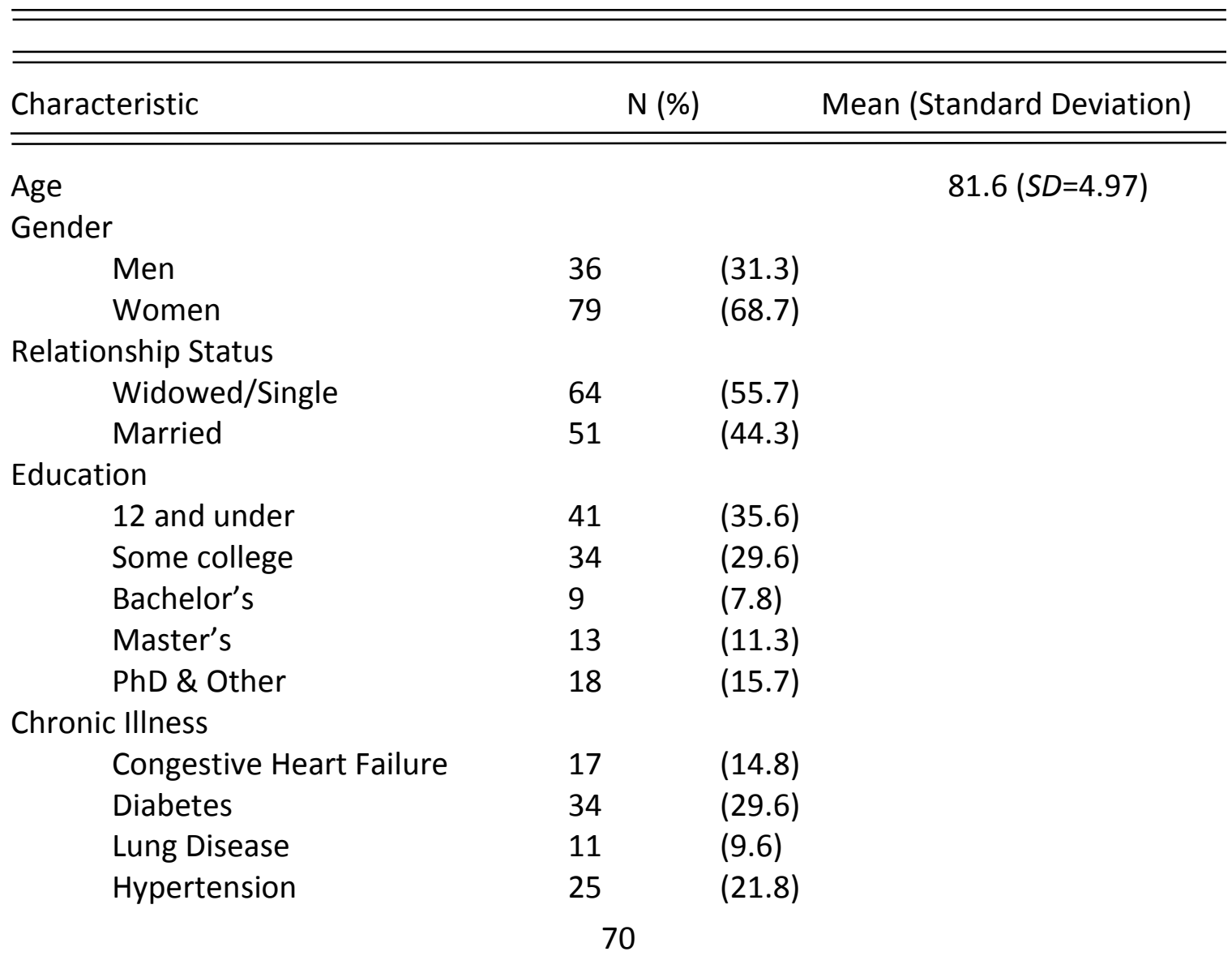


Other

Health Literacy

Limited

Possible Limited

Adequate

Annual Income

Less than $\$ 49,000$

$\$ 50,000-100,000$

Above $\$ 100,000$

Perceived Health Status

Physical Health

Poor

Fair

Good

Excellent

Emotional Health

Poor

Fair

Good

Excellent

Cognitive Health

Poor

Fair

Good

Excellent

Social Health

Poor

Fair

Good

Excellent

DCS Score

SDS Score
1

11

61

42
(52.9)

(36.6)

$22.69(S D=16.40)$

$21.99(S D=5.92)$

\section{Question 1: Personal Characteristics Associated with Decisional Conflict}

To determine if any patient characteristics were associated with decisional conflict, a stepwise multiple linear regression was run to test for associations between patient characteristic variables (gender, relationship status, education, and chronic 
illness type, health literacy measured by the NVS, income, and disease burden measured by the SDS) and the DCS score. The only significant predictor was education (those who had 12 years and under compared to those with a master's degree) $\left(R^{2}=.05 ; B=-11.49\right.$; SE $(B)=4.73 ; \beta=-.22 ; p<.05)$. This finding indicates that individuals with a master's degree tend to have lower DCS scores (See Table 3).

Table 3-3

Multiple Linear Regression

B

SE B

$\beta$

Step 1

Constant

12 and under vs. Master's

23.99

$-11.49$

1.59

4.73

$-.22 *$

Note: $\mathrm{R}^{2}=.05$ for Step $1,{ }^{*} \mathrm{p}<.05$

\section{Question 2: Variables Associated with Preferences for Type of Decision Aid}

Two decision aids had an adequate number of responses to use as dependent variables in the analyses: personal discussions with healthcare workers $(n=49 ; 42.6 \%)$ and booklets/pamphlets ( $\mathrm{n}=19 ; 16.5 \%)$. In univariate logistic regression, using "booklets/ pamphlets "as the dependent variable, disease burden as measured by the SDS score (OR 1.07; C.I., .99-1.16; $p=0.089$ ), was the only predictive variable with $p$ $\leq .10$, but it did not achieve the significance level of $p \leq .05$ for multivariate logistic regression. 
For the decision aid "personal discussions with healthcare providers" the potential predictor variables were gender (OR 0.39; C.I. 0.17-0.93; $p=0.032$ ) and married relationship status (OR 0.50; C.I. 0.23-1.07; $p=0.074$ ). When entered into the stepwise multivariate logistic regression, however, only gender remained statistically significant. This suggests women prefer speaking to their healthcare provider as their decision aid of choice. The $\chi 2$ goodness-of-fit analysis demonstrated the model's adequacy $(p>0.05)$. See Table 4 for results of the logistic regression analyses.

Table 3-4

Analysis of Predictor Variables of Preference for Type of Decision Aid

\begin{tabular}{|c|c|c|c|c|c|c|}
\hline \multirow[b]{2}{*}{ Value } & \multirow[b]{2}{*}{ OR } & \multicolumn{2}{|c|}{ Univariate analysis } & \multirow[b]{2}{*}{ OR } & \multirow{2}{*}{\multicolumn{2}{|c|}{$\begin{array}{l}\text { Multivariate analysis } \\
95 \% \mathrm{Cl} \quad \mathrm{p}\end{array}$}} \\
\hline & & $95 \% \mathrm{Cl}$ & p Value & & & \\
\hline \multicolumn{7}{|c|}{ DV = Booklets/Pamphlet Decision Aid } \\
\hline \multicolumn{7}{|l|}{ Gender } \\
\hline Female & \multicolumn{3}{|c|}{ Reference } & & & \\
\hline Male & 1.77 & 0.64 to 4.86 & .270 & & & \\
\hline \multicolumn{7}{|l|}{ Relationship Status } \\
\hline Widowed/Single & \multicolumn{3}{|c|}{ Reference } & & & \\
\hline Married & 1.49 & 0.56 to 4.00 & .428 & & & \\
\hline \multicolumn{7}{|l|}{ Education } \\
\hline 12 and under & \multicolumn{3}{|c|}{ Reference } & & & \\
\hline Some college & 0.59 & 0.18 to 1.92 & .377 & & & \\
\hline Bachelor's & 0.61 & 0.07 to 5.19 & .652 & & & \\
\hline Master's & 0.91 & 0.19 to 4.47 & .907 & & & \\
\hline PhD \& Other & 0.59 & 0.12 to 2.80 & .505 & & & \\
\hline \multicolumn{7}{|l|}{ Chronic Illness } \\
\hline Other & \multicolumn{3}{|c|}{ Reference } & & & \\
\hline $\mathrm{CHF}$ & 0.28 & 0.04 to 2.23 & .228 & & & \\
\hline Diabetes & 1.96 & 0.71 to 5.41 & .195 & & & \\
\hline Lung Disease & 0.48 & 0.06 to 3.97 & .494 & & & \\
\hline
\end{tabular}


Limited Reference

Possible Limited $2.29 \quad 0.64$ to $8.270 \quad .205$

$\begin{array}{llll}\text { Adequate } & 0.76 & 0.28 \text { to } 2.043 \quad .587\end{array}$

Annual Income

Less than $\$ 49,000$ Reference

$\$ 50,000-100,000$ NA NA $\quad .998$

Above $\$ 100,000$ NA NA .999

$\begin{array}{lll}\text { SDS Score } & 1.069 & 0.99 \text { to } 1.16 \quad 089\end{array}$

DCS Score $\quad 0.99 \quad 0.97$ to $1.03 \quad .831$

DV = Discussion with Healthcare Provider Decision Aid

\begin{tabular}{|c|c|c|c|c|c|c|}
\hline \multicolumn{7}{|l|}{ Gender } \\
\hline Female & \multicolumn{6}{|c|}{ Reference } \\
\hline Male & 0.39 & 0.17 to 0.93 & .032 & 0.46 & 0.19 to 1.14 & .032 \\
\hline \multicolumn{7}{|l|}{ Relationship Status } \\
\hline Widowed/Single & \multicolumn{6}{|c|}{ Reference } \\
\hline Married & 0.50 & 0.23 to 1.07 & .074 & 0.63 & 0.28 to 1.40 & .254 \\
\hline \multicolumn{7}{|l|}{ Education } \\
\hline 12 and under & \multicolumn{6}{|c|}{ Reference } \\
\hline Some college & 0.77 & 0.34 to 1.76 & .539 & & & \\
\hline Bachelor's & 1.76 & 0.45 to 6.93 & .418 & & & \\
\hline Master's & 1.18 & 0.37 to 3.75 & .784 & & & \\
\hline PhD \& Other & 0.83 & 0.30 to 2.33 & .728 & & & \\
\hline \multicolumn{7}{|l|}{ Chronic Illness } \\
\hline Other & \multicolumn{3}{|c|}{ Reference } & & & \\
\hline $\mathrm{CHF}$ & 0.70 & 0.24 to 2.04 & .510 & & & \\
\hline Diabetes & 0.77 & 0.34 to 1.76 & .539 & & & \\
\hline Lung Disease & 0.75 & 0.21 to 2.72 & .660 & & & \\
\hline \multicolumn{7}{|l|}{ Health Literacy } \\
\hline Limited & \multicolumn{3}{|c|}{ Reference } & & & \\
\hline Possible Limited & 1.01 & 0.33 to 3.13 & .984 & & & \\
\hline Adequate & 1.44 & 0.67 to 3.06 & .349 & & & \\
\hline \multicolumn{7}{|l|}{ Annual Income } \\
\hline \multicolumn{7}{|c|}{ Less than $\$ 49,000$ Reference } \\
\hline$\$ 50,000-100,000$ & 1.43 & 0.52 to 3.91 & .491 & & & \\
\hline Above $\$ 100,000$ & 5.78 & 0.63 to 53.41 & .122 & & & \\
\hline SDS Score & 0.97 & 0.91 to 1.04 & .418 & & & \\
\hline DCS Score & 0.99 & 0.98 to 1.02 & .808 & & & \\
\hline
\end{tabular}




\section{Question 3: Feasibility of Online Surveys with Older, Chronically III Elders}

The online survey was opened 74 times, but in 40 cases no data was entered. Of the remaining 34 cases, 19 had partial data, and 15 had complete data. Of the 15 with complete data, the average completion time was 30.5 minutes. All but one of the participants accessed the survey between the hours of 2 p.m. and 9 p.m.

\section{Discussion}

This descriptive, exploratory study explored variables influencing EOL decision making in chronically ill, community dwelling elders aged 75 years or older. Participants in this study were much older (mean age 81.6 years [SD=4.97]) than those in other studies and represent a group that needs to be included in more research. Overall, these participants who were predominately educated ("some college" or less), widowed white women with at least one chronic illness considered themselves healthy (physically, emotionally, socially, and cognitively), had adequate health literacy, a moderate level of symptom distress, and a surprisingly low level of decisional conflict about EOL decisions. Most had participated in EOL discussions in the past and made EOL decisions.

Only one personal characteristic variable-- education, specifically individuals with a master's degree compared to individuals with a $12^{\text {th }}$ grade or lower education -- was significantly associated with lower decisional conflict scores. This finding supports the work of Sudore et al. (2010) who found an association between higher education and lower decisional conflict scores, however in this study the association was limited to advanced degrees-- "some college" or achieving a baccalaureate degree were not significantly associated with lower DC. However, our findings do not support those of 
others who found associations among personal characteristics such as being a woman, being younger (Allen et al., 2008), lower income, health literacy, or fair-to-poor health status (Sudore et al., 2010), and higher decisional conflict. Leighl et al. (2011) also found no associations among age, gender, or anxiety levels and decisional conflict.

The mean DCS score in our sample was fairly low $22.69(S D=16.40)$ which could be attributed to several factors. Our sample's mean age was higher than the literature (81.6 [SD=4.97] versus 60 in the literature). The participants may accept the fact that with their advanced age and chronic illness, the end of life is near, and they are comfortable with the decision they have made. They may have come to terms with their illness and feel comfortable with the realization that their life is nearing its end. Most felt comfortable with their EOL knowledge of options (76.5\%) and treatment $(77.5 \%)$, and many (88.0\%) had EOL discussions in the past, so these factors could contribute to their comfort with the decision.

This data suggests that community-dwelling individuals age 75 or older who have a chronic illness prefer to learn about EOL life-sustaining treatments by talking to their healthcare provider (42.6\%) and/or reading the information in a booklet/ pamphlet (16.5\%). These findings are consistent with others (Chelf et al., 2002; Tung et al., 2011). However, these findings conflict with other studies regarding the use of technologybased decision aids such as video in improving EOL DM by decreasing uncertainty (Allen et al., 2008; Mitchell et al., 2001; Volandes, 2010). This study's participants showed little interest in DVD/videos or internet-based information. There could be several reasons for this lack of interest. Few individuals (3.6\%) in this sample had prior discussions 
regarding EOL that included use of a video or the internet as a decision aid, so they may have had little exposure to this form of DA. It is possible that if the participants in this study were to view a video DA, they may be more accepting of this type of learning. The individuals in this study are older. These study participants grew up in a generation where personal face to face communication (versus texting, instant messaging, etc.) was the primary form of communication, so that preference could be ingrained in them.

A finding of this study that approaches though does not achieve significance is that individuals with more physical symptoms or disease burden, as measured by the SDS score, prefer booklets/pamphlets as the decision aid of choice. Dealing everyday with the negative effects of a chronic illness could potentiate those feelings making them want to use whatever method is easiest and most comfortable for them. It may be easier for individuals with chronic illness to read booklets/pamphlets at home, where they can choose a time when they felt strongest and most comfortable, rather than discussing them with healthcare providers at a time when they might feel ill.

The personal characteristics associated with preference of personal discussions with healthcare providers as a DA included being a woman and being married. However, when both variables were entered into a multivariate logistic regression, only being a woman predicted this preference. Chelf et al. (2002) found women preferred a variety of learning methods. Men may not prefer many different learning methods. They may feel it is more efficient to just have a conversation with their healthcare provider to receive the information they need. 
The Ottawa Decision Support Framework was well suited for this study as it guided the exploration of those determinants of decisions - variables such as sociodemographic data, personal, and clinical characteristics that would be associated with decisional conflict. The framework also identifies that decisional support is a mediating factor between the determinants of decisions and the quality of the decision. If we can explore those decision support factors to identify which types of decision aid would most help individuals in their EOL decision making, we can hopefully improve the quality of their decision making.

The feasibility of using an online survey to collect data in this older population seems limited. We received only 15 complete surveys, despite exhaustive efforts to encourage individuals to fill the survey out electronically. This could indicate a reluctance or discomfort with internet use, similar to findings of Chelf et al. (2002), whose participants, patients with cancer recruited at an outpatient facility with a mean age of 64 , had no interest in computer-assisted learning. It could also reflect problems accessing the survey or with survey length. We had unexpected problems with people not being able to complete the survey on the same computer; once one survey was completed on a particular computer, the survey provider would not allow another individual to access the survey from the same computer. Once we learned of this barrier, we changed the survey settings to allow multiple access times from the same computer. Unfortunately, we have no way of knowing how many other individuals may have used a community or shared computer and encountered this same error message, preventing them from completing the survey online. 
Only a small percentage of online surveys that were opened were completed.

The length of the survey was quite long. Individuals could have wanted to complete the survey but once they identified how long it was, that could have deterred them from completing. Curiosity could explain the large number of individuals who accessed the site but did not enter data. The survey link was distributed to the primary investigator's friends on Facebook, so many people could have been curious to see what the survey was about without meeting the inclusion criteria or having any intention of completing the survey. Recruiting this sample, of 115 older chronically ill adults living independently, proved challenging and time consuming. The PI recruited at 14 sites where seniors congregate in addition to utilizing social media, word of mouth and direct e-mail. The online survey web address was sent out to over 1600 individuals on Facebook alone. The primary researcher sent it to all individuals in her friends list $(n=403)$ and a peer volunteered to send the survey link to everyone in her friends list ( $n=1267)$ requesting those online friends to forward the link to anyone they thought would meet the inclusion criteria and agree to complete the survey.

Participants recruited for paper-based surveys were hesitant to provide their names (informed consent sheet) and to fill out paperwork. They worried that I was going to keep contacting them. One gentleman stated, "People are always calling wanting something." I assured them repeatedly that they would not be contacted again regarding this study and that no identifying information other than their name was collected, which appeased most individuals who expressed these concerns. However, the need to provide names may have discouraged others from participating. 
Another challenge with this study was the length of the survey, which may have discouraged its completion. The average completion time for paper surveys was approximately 18 minutes, which may be long in this age group. Several participants completing paper-based surveys said it was too long and took too much time to fill out. One participant said, "I have a master's degree and even this is too long for me". Shortening the survey could help in future research. One way to shorten the survey would be to use the lower literacy version of the DCS which has 10 questions instead of the 16 item version used.

\section{Limitations}

The study had several limitations. Several threats to internal validity included selection bias (convenience sample) statistical bias (small sample size limited necessary power to analyze types of decision aids other than booklets/pamphlets and personal discussion with healthcare providers), and recall bias (the instruments were all selfreport). Although the instruments utilized had reported validity and reliability in other populations, we did not know how they would perform in our sample. To address this, we ran reliability testing on the Symptom Distress Scale and the Decisional Conflict Scale in our sample. They both appear reliable with Cronbach's alpha of 0.81 and 0.97 , respectively. We ran a factor analysis on the Decisional Conflict Scale, which has five sub-scales. Our factor analysis resulted in only two factors, so this scale appears to be functioning somewhat differently in our group. The two factors were highly correlated, however. Generalizability is limited due to the sample's homogeneity in terms of race (all Caucasian) and location (the sample was recruited from one area in Central Illinois). 


\section{Conclusion}

End-of-life decision making is a phenomenon worth investigating despite its sensitive nature. Health professionals benefit from knowing the best way to educate individuals about end-of-life options and this study sheds needed light on the topic. Findings from this study indicate that chronically ill, community dwelling elders over 75 years old prefer to learn through more traditional methods, rather than technological ones. Their highest preference for decision aids is personal discussions, followed distantly by reading booklet/pamphlets. This group had low decisional conflict overall, and past experience with EOL discussions and decisions. Those with a master's degree or more education level versus $12^{\text {th }}$ grade or lower had less decisional conflict. While they rated their health as good overall, it appeared that those with more symptom distress preferred booklets/pamphlets as a decision aid but did not reach statistical significance. Women preferred personal discussions with healthcare providers compared with men. Tailoring education strategies to an individual's personal characteristics and preferences may lead to better end-of-life decisions and less decisional conflict.

\section{Implications for Practice}

This study provides insight into factors that associate with decisional conflict and decision aid preferences. Providing end-of-life information in an effective method tailored to individual preferences could enhance healthcare discussions and education. Practitioners need to assess their patients' decisional conflict and preferred type of decision aid. The Decisional Conflict Scale was found reliable and valid in this sample of 
individuals, so it could be used in practice. Clinicians need to develop educational materials utilizing modes that patients prefer to assist them in EOL DM. Most likely, the answer will not be a one size fits all solution. Identifying the most desired DA modes assists the healthcare community develops teaching tools designed in ways that will benefit the consumer and multiple tools will most likely be the answer. Educators must continually strive to assess the learning preferences of their audience and provide effective therapeutic teaching materials.

\section{Implications for Research}

The mean age of participants in the EOL literature was 60 , a fairly young age for those considering EOL decisions. Elders who are 75 and older represent a cohort of individuals who grew up in another era and may view death differently, such as viewing death as imminent or as an opportunity to join loved ones who have already died (Gott, Small, Barnes, Payne, \& Seamark, 2008). This study adds to the EOL decision making science. It is important we include the oldest old in research to determine their preferences. Studies are needed in those participants older than 60 to identify preferred learning methods to develop DAs tailored to the needs of those who could benefit in EOL DM assistance. Interventional studies could be helpful with older individuals to expose them to alternate methods of technology-based decision aids.

This study looked at individuals living independently in the community, while most research in this area accessed participants in tandem with healthcare services, either at their primary care physicians' office or in the hospital. We need to reach out to individuals in the community as well as access them in the healthcare environment. 
Researchers could explore methodological studies to identify better strategies to identify the oldest old who are still living independently. Further research could explore the perceptions of these elders that may contribute to reluctance to participate in research, including weariness, fears, misconceptions, or sensitivities that prevent them from participating in research. 


\section{References}

Allen, R.S., Allen, J.Y., Hilgeman, M.M. \& DeCoster, J. (2008). End-of-life decision-making, decisional conflict and enhanced information: Race effects. Journal of American Geriatric Society, 56, 1904-1909.

American Nurses Association (2001). Peaceful death: Recommended competencies and curricular guidelines for end-of-life nursing care. Retrieved on April 1, 2011 from http://www.aacn.nche.edu/Publications/deathfin.htm.

Beckstrand, R.L., Callister, L.C., \& Kirchhoff, K.T. (2006). Providing a "Good Death:" Critical care nurses' suggestions for improving end-of-life care. American Journal of Critical Care, 15, 38-45.

Beckstrand, R.L., Smith, M.D., Heaston, S., \& Bond, A.E. (2008). Emergency nurses' perceptions of size, frequency, and magnitude of obstacles and supportive behaviors in end-of-life care. Journal of Emergency Nursing, 34, 290-300.

Chelf, J.H., Deshler, A., Thiemann, K., Dose, A.M., Quella, S.K. \& Hillman, S. (2002). Learning and support preferences of adult patients with cancer at a comprehensive cancer center. Oncology Nursing Form, 29, 863-867.

Dales, R.E., O’Connor, A., Hebert, P., Sullivan, K., McKim, \& Llewellyn-Thomas, H. (1999). Intubation and mechanical ventilation for COPD*: Development of an instrument to elicit patient preference. CHEST, 116, 792-800.

Davison, S.N. (2010). End-of-life care preferences and needs: Perceptions of patients with chronic kidney disease. Clinical Journal of American Society of Nephrology, 5, 195-204.

Edwards, A. \& Elwyn, G. (2001). Evidence-Based patient choice. Oxford: Oxford University Press.

El-Jawahri, Al., Podgurski, L.M., Eichler, A.F., Plotkin, S.R., Temel, J.S., Mitchell, S.L., Chang, Y., Barry, M.J. \& Volandes, A.E. (2009). Use of video to facilitate end-oflife-discussions with patients with cancer: A randomized controlled trial. Journal of Clinical Oncology, 28, 305-310.

Gott, M., Small, N., Barnes, S., Payne, S., \& Seamark, D. (2008). Older people's views of a good death in heart failure: Implications for palliative care provision. Social Science \& Medicine, 67, 1113-1121.

Heyland, D.K., Frank, C., Groll, D., Pichora, D., Dodek, P., Rocker, G., \& Gafni, A. (2006). Understanding cardiopulmonary resuscitation decision making. CHEST, 130, 419428. DOI 10.1378/chest. 130.2 .419

IBM Corp. Released 2011. IBM SPSS Statistics for Windows, Version 20.0. Armonk, NY: IBM Corp.

Jacobsen, M.J. \& O’Connor, A. (1999). Population needs assessment. Retrieved from www.ohri.ca./decisionaid

Janssen, D.J., Spruit, M.A., Schols, J.M., \& Wouters, E. F. (2011). A call for high-quality advance care planning in outpatients with severe COPD or chronic heart failure. CHEST, 139, 1081-1088. Retrieved from http://dlestjournal.chestpubs.org/data/Journals/CHEST/22096/101753.pdf 
Leighl, N.B., Shepherd, H.L., Butow, P.N., Clarke, S.J., McJannett, M., Beale, P.J. ... \& Tattersall, M.H.N. (2011). Supporting treatment decision making in advanced cancer: A randomized trial of a decision aid for patients with advanced colorectal cancer considering chemotherapy. Journal of Clinical Oncology, 29, 1-9.

Marbach, T.J. \& Griffie, J. (2011). Patient preferences concerning treatment plans, survivorship care plans, education, and support services. Oncology Nursing Forum, 38, 335-42. Doi: 10.1188/11.ONF.335-342.

Mathieu, E., Barratt, A.L., McGeechan, K., Davey, H.M., Howard, K., \& Houssami, N. (2010). Helping women make choices about mammography screening: An online randomized trial of a decision aid for 40-year-old women. Patient Education and Counseling, 81, 63-72.

McCorkle, R., Cooley, M.E. \& Shea, J.A. (2000). A user's manual for the Symptom Distress Scale. Philadelphia: University of Pennsylvania.

Mitchell, S.L., Tetroe, J., \& O'Connor, A.M. (2001). A decision aid for long-term tube feeding in cognitively impaired older persons. Journal of American Geriatric Society, 49, 313-316.

Murray, M.A., Miller, T., Fiset, V., O’Connor, A., \& Jacobsen, M.J. (2004). Decision support: Helping patients and families to find a balance at the end of life. International Journal of Palliative Nursing, 10, 270-277.

O'Connor, A.M. (1995) Validation of a Decisional Conflict Scale. Medical Decision Making, 15, 25-30.

O’Connor, A.M. (1999). The Decisional Conflict Scale. Retrieved from www.ohri.ca/decisionaid.

O’Connor, A.M. (2006) Ottawa decision support framework to address decisional conflict. Retrieved from http://decisionaid.ohri.ca/docs/develop/ODSF.pdf.

O'Connor, A.M., Drake, E.R., Fiset, V., Graham, I.D., Laupacis, A., \& Tugwell, P. (1999). The Ottawa patient decision aids. Effective Clinical Practice, 2, 163-170.

O'Connor, A.M., Drake, E.R., Wells, G.A., Tugwell, P., Laupacis, A., \& Elmslie, T. (2003). A survey of the decision-making needs of Canadians faced with complex health decisions. Health Expectations, 6, 97-109.

O'Connor, A.M. (2006) Ottawa decision support framework to address decisional conflict. Retrieved from http://decisionaid.ohri.ca/docs/develop/ODSF.pdf

O'Connor, A.M., Tugwell, P., Wells, G.A., Elmslie, T., Jolly, E., Hollingworth, G., McPherson, R., Bunn, H., Graham, I., \& Drake, E. (1998). A decision aid for women considering hormone therapy after menopause: decision support framework and evaluation. Patient Education and Counseling, 33, 267-279.

Porensky, E.K. \& Carpenter, B.D. (2008). Knowledge and perceptions in advance care planning. Journal of Aging and Health, 20, 89-106.

Ragsdale, D. \& Morrow, J. R. (1990). Quality of life as a function of HIV classification. Nursing Research, 39, 355-359.

Reinke, L.F., Griffith, R.G., Wolpin, S., Donesky-Cuenco, D., Carrieri-kohlman, V., \& Nguyen, H.Q. (2011). Feasibility of a webinar for coaching patients with chronic 
obstructive pulmonary disease on end-of-life communication. American Journal of Hospice Palliative Care, 28, 147-152.

Song, M. \& Sereika, S.M. (2006). An evaluation of the decisional conflict scale for measuring the quality of end-of-life decision making. Patient Education and Counseling, 61, 397-404.

Steinhauser, K.E., Clipp, E.C., McNeilly, M., Christakis, N.A., McIntyre, L.M., \& Tulsky, J.A. (2000). In search of a good death: Observations of patients, families, and providers. Annals of Internal Medicine, 132, 825-832.

Sudore, R.L., Schillinger, D., Knight, S.J. \& Fried, T.R. (2010). Uncertainty about advance care planning treatment preferences among diverse older adults. Journal of Health Communication, 15, 159-171.

SUPPORT Principal Investigators. (1995). A controlled trial to improve care for seriously ill hospitalized patients: The study to understand prognoses and preferences for outcomes and risks of treatment (SUPPORT). Journal of American Medical Association, 274, 1591-1598.

Thelan, M. (2005). End-of-life decision making in intensive care. Critical Care Nurse, 25, 28-37.

Tung, E.E., Vickers, K.S., Lackore, K., Cabanela, R., Hathaway, J., \& Chaudhry, R. (2011). Clinical decision support technology to increase advance care planning in the primary care setting. American Journal of Hospice \& Palliative Medicine, 28, 230235.

Turk, M.A., (2009). Health, mortality, and wellness issues in adults with cerebral palsy. Development Medicine \& Child Neurology, 51, 24-29.

United States Census Bureau (2010). State \& County QuickFacts. Retrieved from http://quickfacts.census.gov/qfd/states/17/17143.html on July 6, 2011.

Vidal, A.C. \& Pandiella, A. (2010). COPD: A model for using advance directives and care planning. Archivos De Bronconeumologia, 46, 325-331.

Volandes, A.E., (2007). Using video images of dementia in advance care planning. Archives of Internal Medicine, 167, 828-833.

Volandes, A.E., (2008). Overcoming educational barriers for advance care planning in Latinos with video images. Journal of Palliative Medicine, 11, 700-706.

Volandes. A.E. (2011). Assessing end-of-life preferences for advanced dementia in rural patients using an educational video: A randomized controlled trial. Journal of Palliative Medicine, 14, 169-177.

Volandes, A.E., Barry, M.J., Chang, Y., \& Paasche-Orlow, M.K. (2010). Improving decision making at the end of life with video images. Medical Decision Making, 30, 29-34.

Volandes, A.E., Mitchell, S.L., Gillick, M.R., Chang, Y., \& Paasche-Orlow, M.K. (2009). Using video images to improve the accuracy of surrogate decision-making: $A$ randomized controlled trial. Journal of American Medical Directors Association, $10,575-580$.

Von Gunten, C.F. (2005). Interventions to manage symptoms at the end of life. Journal of Palliative Medicine, 8, 88-94. 
Weiss, B.D., Mays, M.Z., Martz, W., Castro, K.M., DeWalt, D.A., Pignone, M.P., Mockbee, J., \& Hale, F.A. (2005). Quick assessment of literacy in primary care: The newest vital sign. Annals of Family Medicine, 3, 514-522. doi: 10.1370/afm.405.

Wilson, K.G., Aaron, S.D., Vandemheen, K.L., Hebert, P.C., McKim, D.A., Fiset, V., Graham, I.D., Sevigny, E., \& O'Connor, A.M. (2005). Evaluation of a decision aid for making choices about intubation and mechanical ventilation in chronic obstructive pulmonary disease. Patient Education and Counseling, 57, 88-95.

Yeakle, J. \& Allen, R. (2007). Piloting EDMAC: The end-of-life decision making and memory complaint project. University of Alabama Mcnair Journal, 7, 195-215. Retrieved from http://www.graduate.ua.edu/mcnair/journals/2007/Yeakle.pdf 